Rhode Island College

Digital Commons @ RIC

2016

\title{
Studying School Improvement Teams to Analyze Multiple Stakeholder Engagement in Decision-Making in Public Education
}

Julie A. DiBari

Rhode Island College

Follow this and additional works at: https://digitalcommons.ric.edu/etd

Part of the Education Economics Commons, and the Other Education Commons

\section{Recommended Citation}

DiBari, Julie A., "Studying School Improvement Teams to Analyze Multiple Stakeholder Engagement in Decision-Making in Public Education" (2016). Master's Theses, Dissertations, Graduate Research and Major Papers Overview. 167.

https://digitalcommons.ric.edu/etd/167

This Dissertation is brought to you for free and open access by the Master's Theses, Dissertations, Graduate Research and Major Papers at Digital Commons @ RIC. It has been accepted for inclusion in Master's Theses, Dissertations, Graduate Research and Major Papers Overview by an authorized administrator of Digital Commons @ RIC. For more information, please contact digitalcommons@ric.edu. 
STUDYING SCHOOL IMPROVEMENT TEAMS TO ANALYZE MULTIPLE STAKEHOLDER ENGAGEMENT IN DECISION-MAKING IN PUBLIC EDUCATION

BY

JULIE A DIBARI

A DISSERTATION SUBMITTED IN PARTIAL FULFILLMENT OF THE REQUIREMENTS FOR THE DEGREE OF DOCTOR OF PHILOSOPHY IN EDUCATION

UNIVERSITY OF RHODE ISLAND

AND

RHODE ISLAND COLLEGE 


\section{DOCTOR OF PHILOSOPHY DISSERTATION}

OF

Julie A. DiBari

Dissertation Committee

Major Professor Marie Lynch

David Brell

Peter Adamy

Kathy Peno

RIC Donald Halquist

Dean, Feinstein School of Education - RIC

URI Nasser H. Zawia

Dean, The Graduate School, URI

UNIVERSITY OF RHODE ISLAND

AND

RHODE ISLAND COLLEGE 


\begin{abstract}
Since the Industrial Revolution, when schools became larger and the missions broader, there has been an attempt by a wide range of stakeholders to have a voice in public education. More recently, through No Child Left Behind and Race to the Top, the federal government began to increase requirements for multiple stakeholder engagement in decision-making for schools requesting Title I funds. As the need for a more educated workforce has grown, businesses have also sought to have a voice in improving education. Additionally, experts in the field of parent, school and community engagement, have called for the inclusion of parents, diverse faculty, staff, and community voice. An outgrowth of the federal, business, and family, school, community partnership historical landscapes, has been the development of school improvement teams, which have become increasingly common, typically with a goal of bringing together multiple stakeholders to provide input into decision-making for school improvement. However, there has been little research on the make-up of these teams, the issues they address, how stakeholders on the team are engaged, and whether the teams are connected to any other efforts in the school focused on engagement. This case study analysis richly describes the school improvement team processes of two schools in the Northeast region. The results of this study indicate that the goal of engaging stakeholders beyond administrative staff in consensus-driven, decisionmaking teams is yet to be realized, even among schools that highly value the input of teachers, parents, youth and community partners and have rich engagement opportunities for these groups in other areas of the school. This study also offers insights into how schools might improve in these areas in the future.
\end{abstract}




\section{ACKNOWLEDGEMENTS}

Thank you to my husband and children for supporting me in completing the program and pursuing my passion for improving education through study and research. Thank you to my committee, for your time both as a group and individually in helping me to shape my research questions and to grow as researcher Thank you to Dr. Marie Lynch for chairing my committee and patiently going through many, many drafts and revisions as I narrowed down my literature review and analysis of findings. And for providing support and encouragement along the way.

Thank you to Dr. David Brell for the many hours he spent helping me think through my theoretical framework, always taking the time to understand my perspective on the topic and provide helpful insight, advice and theorists to explore.

Thank you to Dr. Peter Adamy for your support in helping me to explore a wide variety of qualitative research approaches and helping me to identify the approach best suited to this work.

Thank you also to Dr. Kathy Peno for offering your helpful expertise on qualitative research and knowledge of social constructivism as well as your helpful insight into other areas of this work.

Thank you to my colleagues in the URI/RIC PhD in Education program and all the professors I studied with during my time in the institution.

Thank you also to all my colleagues in nonprofit and education sectors who expand my thinking every day and who work so passionately to improve educational outcomes for all our children. 


\section{TABLE OF CONTENTS}

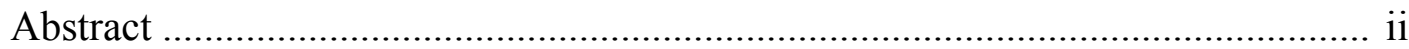

Acknowledgements........................................................................................

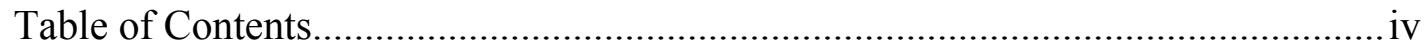

CHAPTER 1: Statement of the Problem and Introduction .................................... 1

Statement of the Problem ........................................................................... 1

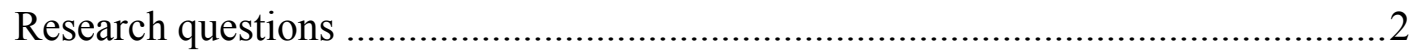

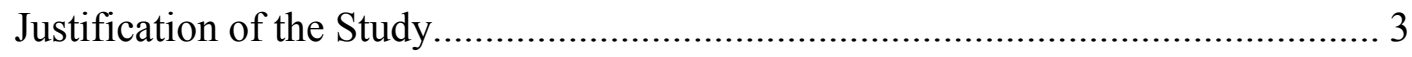

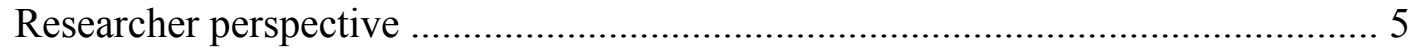

CHAPTER 2: Review of Literature ............................................................. 8

History of Multiple Stakeholder Engagement in Education ................................ 8

Theoretical Framework . ............................................................................ 9

- Defining Multiple Stakeholder Engagement .......................................... 10

- Defining Authentic Engagement ....................................................... 11

- Theories from the Field of Education ......................................................... 11

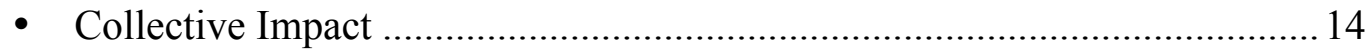

- Organizational Change Management Theories ....................................... 15

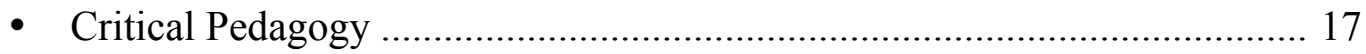

Improved Student Outcomes as a Result of Multiple Stakeholder Engagement ...... 18

Elements of Successful School, Parent, Community Partnership ..........................21

Models for Successful School, Parent, Community Partnership ........................... 22

Organic Approaches to School, Parent, Community Partnership ...........................23

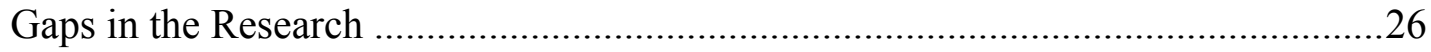




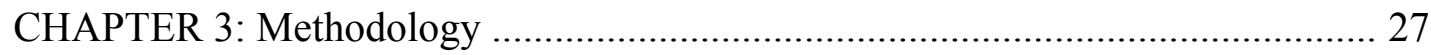

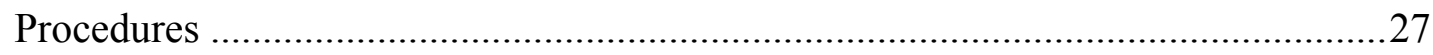

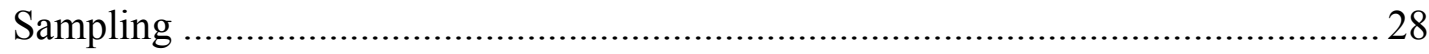

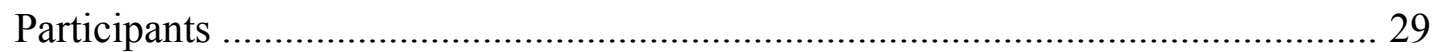

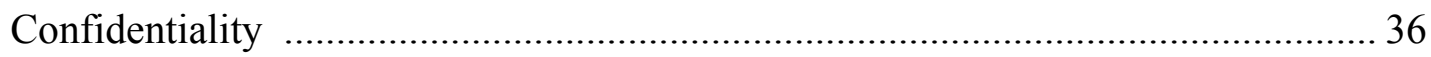

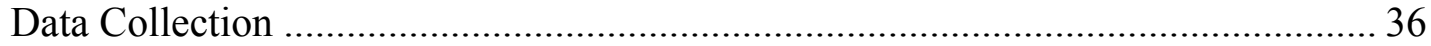

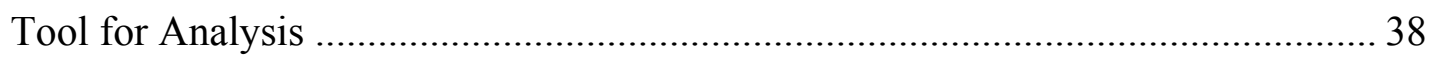

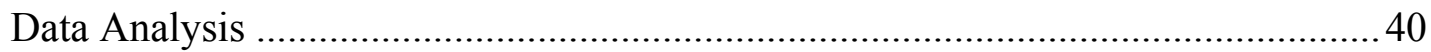

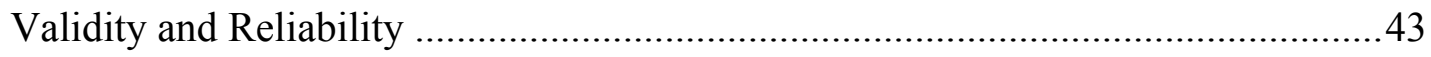

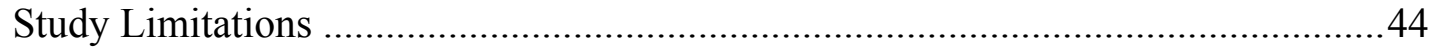

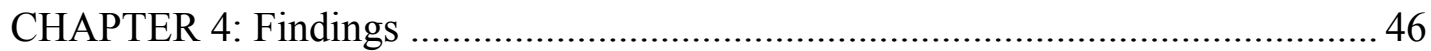

Descriptions of Schools and School Improvement Team Legislation ........................46

Q1: Who is engaged on the school improvement teams and why? .......................... 56

- Outline of the stakeholders that were included and not included ...................56

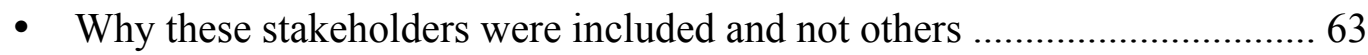

Q2: How school improvement team members were engaged ................................... 70

- Consensus driven decision making as core to feelings of engagement .........70

- Additional findings related to how team members are engaged.......................74

Q3: The types of decisions school improvement team members were engaged in .. 75

- Shared areas for discussion, not decision ...................................................... 75

Q4: The facilitators' role in school improvement teams ......................................... 79

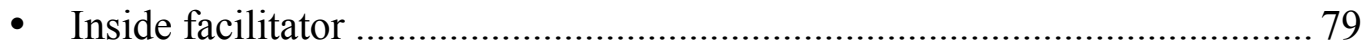

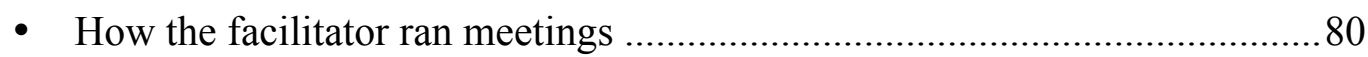


Q5: Strengths and difficulties shared by school improvement teams 81

- Technology as a strength and a challenge. .81

- The budget as a challenge to consensus driven decision making .. 82

- Challenges using assessment data .83

Q6: Other school engagement efforts connected to the school improvement team . 86

- Rich engagement efforts outside the school improvement team and informal connections back to the school improvement team .86

Q7: Authentic engagement, adaptive leadership, and collaborative governance ..... 93

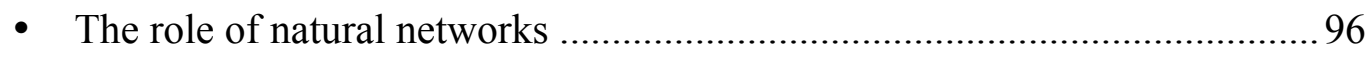

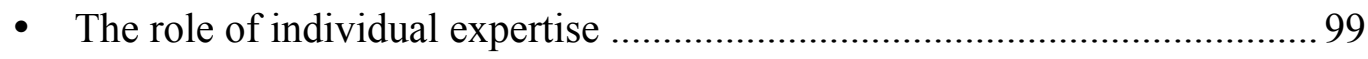

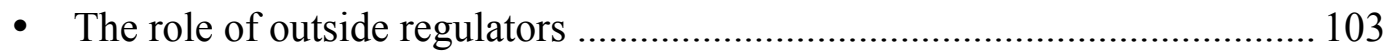

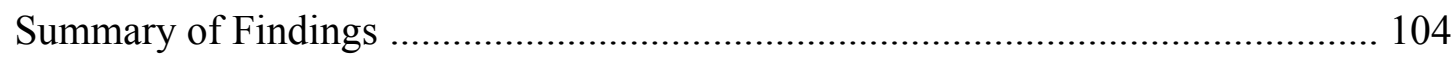

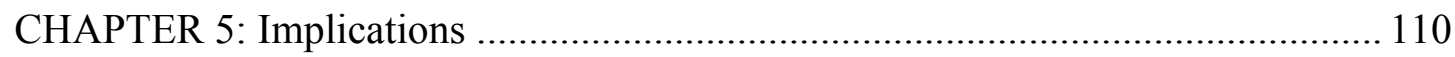

- Future research..................................................................................... 116

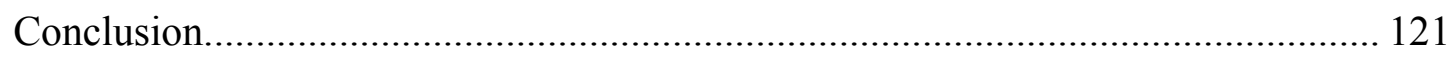

\section{APPENDICES}

A. Consent Form for Research ............................................................. 123

B. Stakeholder Interview Instrumentation ............................................... 125

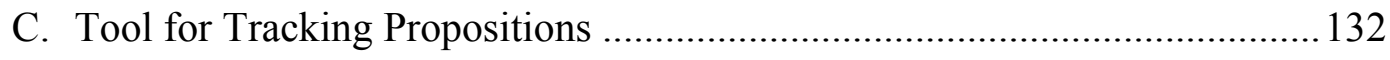

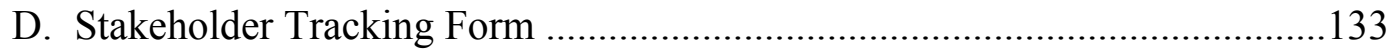

E. Tool for Tracking Codes ................................................................. 134

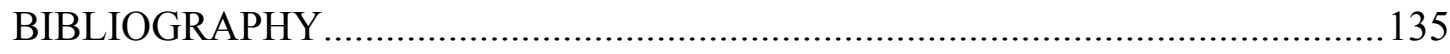




\section{CHAPTER 1 - STATEMENT OF THE PROBLEM AND INTRODUCTION}

\section{Statement of the Problem}

From the earliest inception of public schools, beginning with Horace Mann and his rationale for public education, and continuing with Dewey's connection between education and democracy, it has been assumed that public schools would be a vehicle for solving social problems (Noddings, 2013; Tyack \& Cuban, 1997). To that end, the public has always been interested in public education and how it is delivered. However, despite many proposed reforms to improve education over the past 100 years, based on significant research, the model of traditional public education has changed very little, with the exception that there has been a significant change in the diversity of students who are provided access to public schools (Tyack \& Cuban, 1997; Education News, 2016). This diversity calls for the engagement of a wider range of stakeholders in the decision-making process for school improvement (Comer, 1996; Epstein, 2011). In recent years, school improvement research from the field of school, family, and community partnerships has begun to show that schools that have open engagement with parents, youth, and the community make improvements that lead to a better school climate and better educational outcomes for a diverse range of students. (Cook, Murphy \& Hunt, 2000; Epstein, 2005; Henderson \& Mapp, 2002; Malloy \& Rayle, 2000; Sanders 1996,1998; Sheldon 2003, 2010; Sheldon \& Epstein 2002, 2005).

Some believe that the failure to engage multiple stakeholders in decision-making in public schooling undermines the task of positive, productive education improvement (Apple, 2008; Epstein 2011; Brown University Lipsitt-Duchin Lecture in Child and Youth Behavior and Development, 2013). However, the definition of "community" is not 
clear in the research, and the role of student voice has not been adequately investigated (Epstein, 2011; Hope 2012). In addition, reviews of education research journals, through EBSCOhost and JSTOR, revealed that little is known about how schools engage multiple stakeholders in decision-making with respect to school improvement teams, which have become increasingly common for engaging multiple stakeholder perspectives in schools, either as state department of education requirements or through state legislation. (Commonwealth of Virginia Department of Education; Louisiana Department of Education, 2010; Massachusetts Department of Secondary and Elementary Education, 2014; Michigan Legislature, 2014; North Carolina General Assembly 2014; Oklahoma State Department of Education, 2014; Pennsylvania State Education Association, 2007; Rhode Island General Assembly, 2011; West Virginia Department of Education, 2013). Thus, this study looked at how two high schools implemented their school improvement team process. The specific questions the research sought to answer included:

1) Who are the stakeholders that are engaged in school improvement teams, and why were they chosen or asked to participate?

2) In what ways, if any, are the stakeholders engaged in school improvement teams?

3) What types of decisions do the stakeholders engage in? What types of decisions are they not engaged in?

4) In what ways, if any, do facilitators support the process of multiple stakeholder engagement in school improvement teams?

5) What are the strengths and difficulties shared by schools attempting multiplestakeholder engagement through school improvement teams? 
6) Are there other multiple stakeholder engagement efforts connected to school improvement teams?

7) Is there evidence of authentic engagement (Friere, 1993), adaptive leadership (Heifetz, et al, 2009), and/or collaborative governance (Ansell \& Gash, 2007; Kania \& Kramer, 2011)?

\section{Justification of the Study}

Since the Industrial Revolution, when schools became larger and in mission necessarily broader, there has been an attempt by a wide range of stakeholders to have a voice in public education (Brill, 2010; Epstein, 2011; Ravitch, 2010; Tyack \& Cuban, 1997). Since the 1960s, schools have served a more diverse population through desegregation, the federal government's role has expanded, and calls for more parent engagement in education have become more prevalent (Brill, 2010; Comer, 1996; Epstein, 2011; Ravitch, 2010; Tyack \& Cuban, 1997; U.S. Congress, 1965). Moreover, in the 1980s, site-based management models began to take shape due to an interest in the engaging those within the local school in decision-making, in particular teachers, with an aim toward school improvement (Midgley \& Wood, 1993).

Since 2001, through legislation such as No Child Left Behind (2001) and Race to the Top (U.S. Department of Education, 2009), the federal government began to increase requirements for multiple stakeholder engagement in decision-making for schools requesting Title I funds (U.S. Department of Education, 2001, 2009, 2014). As businesses struggled to find a more educated workforce they also began to seek to have a voice in improving education, primarily through the charter school movement (Brill, 2011; Epstein, 2011; Ravitch, 2010). Additionally, leading experts in the field of parent 
engagement called for the inclusion of parents and the community as part of an overall effort to make substantial school improvements (Comer, 1996; Epstein, 2011).

An outgrowth of the historical landscapes described above has been the development of school improvement teams, which have become increasingly common across schools, districts, and states. Typically, the goal of these teams has been bringing together multiple stakeholders (including parents, teachers, community members, and sometimes youth) to provide collective decision-making opportunities for school improvement (Barnes, 2004; Commonwealth of Virginia Department of Education; Louisiana Department of Education, 2010; Massachusetts Department of Secondary and Elementary Education, 2014; Michigan Legislature, 2014; North Carolina General Assembly 2014; Oklahoma State Department of Education, 2014; Pennsylvania State Education Association, 2007; Rhode Island General Assembly, 2011; West Virginia Department of Education, 2013). One of the key challenges for schools is to determine how to leverage effectively the knowledge and resources of multiple stakeholders in school improvement efforts (Sanders, 2005).

However, reviews of educational journals on EBSCOhost and JSTOR, using search terms such as "school improvement team," "site-based team," and "parent, school, community," reveals relatively little research on the impact of school improvement teams or other school efforts to engage multiple stakeholders in critical decision-making designed to improve outcomes. Thus, this research study aims to describe richly efforts underway at two Northeast high schools that incorporate multiple stakeholders in decision-making as part of their state-mandated school improvement teams. Consideration was given to the role of businesses, government agencies, parents, youth, 
teachers, educational researchers, and nonprofits as prominent stakeholders.

\section{Researcher Perspective}

As a researcher, I bring a unique combination of life experiences that influences what I choose to study and how I approach the work. Growing up as a foster youth, in the care of the Department of Social Services, I became acutely aware of the value of the voice of the person being served in systems that aim to meet the needs of a particular population, and the surprising lack of attention to that voice. As a parent of young children, I also see clearly the value of the voice of parents and caregivers in decisionmaking, as the adults most likely to be able to articulate the social and emotional needs of the children and youth in the school system and as critical partners in educational success. In addition to my personal background, I also have a varied professional background that widens my view; first, as an executive at a nonprofit working with vulnerable youth, many of whom were not succeeding in the traditional education model and were dropping out, and later as a consultant to the nonprofit and public sectors working with a wide range of nonprofits and public agencies seeking to support student achievement in school. Through this background I became convinced that public agencies, nonprofits, parents, and students have a valuable perspective and an important role to play in education as experts in mental health, social work, substance abuse, youth engagement, and other critical areas. As an MBA with professional experience in both the for-profit and non-profit sectors and experience in executive positions hiring and overseeing staff, I have learned that society and the work world demand a wide range of skills. As an employer myself I have often been concerned about the gap between what children and youth are learning in school and what is needed in the workplace and, as 
such, understand the role that business leaders could play in school improvement. As a $\mathrm{PhD}$ candidate in education, I have learned about the wealth of teacher knowledge and educational research that can help illuminate promising practices that serve to improve schools, based on teachers, administrators, educational research, and educational researchers working together. As a consultant, focused on facilitating organizations and individuals working together to solve social problems, I see the tremendous value of multiple stakeholder engagement in decision-making and the role that outside facilitation and research can play in that work.

Because I also have a deep concern for enhancing the success of marginalized populations, such as underserved racial and ethnic groups and groups with low socioeconomic status, I also recognize the necessity of including diverse perspectives. I am interested in learning about the process of engaging a broad group of stakeholders together in decision-making and determining how these stakeholders are "authentically" engaged. Borrowing from Freire (1993) and Giroux (2011), I hold a belief that people are empowered to participate in a process only when they are educated about the larger systems at work, are aware of their individual needs, and know how those things connect. This includes the belief that people must have agency in a change process. It is my belief that the inclusion of one voice in a democratic society does not necessarily have to result in the oppression of another voice. I believe that consensus can be reached and that the democratic inclusion of multiple viewpoints will result in a more balanced educational system (Dewey 1916, 1997). However, to avoid oppression it is important to be clear about underlying principles and different perspectives/experiences that may impact groups differently within the educational system. 
It should also be noted that while I clearly feel that multiple stakeholder engagement is extremely important for public schools, I also recognize that it is a tremendous organizational management challenge. As a result, a key focus of this investigation was to identify common themes related to these challenges and how schools address them in the context of school improvement teams. The focus of the research study was on how two high schools attempted to engage multiple stakeholders in decision-making on school improvement teams, as required by legislation, with emphasis on who the schools included, how they engaged participants, and why they engaged these stakeholders in the ways that they did. The goal is to provide information to school leaders and researchers that will help them to better understand school improvement teams and multiple stakeholder engagement efforts. 


\section{CHAPTER 2: REVIEW OF LITERATURE}

\section{History of Multiple Stakeholder Engagement in}

Decision-Making in Public Education

Throughout much of U.S. history, school has been seen as a valuable institution, first with a primary focus on the moral and practical education of the individual learner who could afford to attend school, and later as a means of strengthening society as a whole through public education (Noddings, 2013; Tyack \& Cuban, 1997). More recently, there has also been increased attention regarding the need for parent and community voices to play an active role in educational decision-making, as schools are a public institution (Weng, 2008; Westbury, 2008). Moreover, in the last two decades, businesses, nonprofit leaders, and community advocates, previously left out of the dialogue within public education, began to push for educational reforms and have had considerable influence over what happens in schools (Brill, 2011; Ravitch, 2010). Thus, multiple stakeholder engagement has become part of the educational reform landscape, inclusive of parent, business, and broader community involvement to improve schools (Epstein, 2011; U.S. Department of Education, 2009).

Additionally, federal legislation such as No Child Left Behind (2001) and Race to the Top (U.S. Department of Education, 2009) have included requirements for engagement. In turn, there has been an increased focus on the important role of multiple stakeholder engagement to improve schools (Epstein, 2013; U.S. Department of Education, 2011). Efforts toward engaging multiple stakeholders have created structures such as school improvement teams, which are now mandatory in some states (U.S. 
Department of Education, 2013; Rhode Island General Assembly, 2011; West Virginia Department of Education, 2013).

Although teachers are an important source of knowledge and information regarding how schools should function, historically their voice has not been given the position that it should (Hiebert \& Stigler, 2009). Moreover, other voices, including parents, students, individuals of color, immigrant communities, school administrators, communities with fewer resources, individuals/groups with business acumen, educational researchers, health and mental health professionals, social workers, and child development specialists should be considered as well (Bloomberg Business Weekly, 2013; Comer, 2004; Epstein, 2011; Pew Charitable Trust, 2011). A more respectful and inclusive dialogue around school improvement is needed (Comer, 2004; Corcoran, 2012; Owens \& Valensky, 2011).

\section{Theoretical Framework}

A pragmatic, participatory worldview underlies this study to learn more about school improvement team decision-making. Pragmatically, the study was approached with the most appropriate methodology for understanding the issue and presenting the research to the field, without a particular concern for the ontological question of whether one can achieve an objective truth or reality, but instead with a focus on the need to make practical decisions with the best possible knowledge available (Biesta \& Burbules, 2003; James, 1991). It is participatory in the sense that it presupposes that multiple stakeholders' perspectives should be engaged in decision-making in public education (Dewey, 1997a, 1997b). 
Several theories supported the theoretical framework that guided the development of tools to conduct the research. For instance, theories from leaders in the field of family, school, and community partnerships include James Comer's (2004) emphasis on the role of student-centered practice, and Joyce Epstein's (2011) theory of "overlapping spheres," the latter highlighting the overlapping roles of parents, schools and communities, in contrast to other views that see these spheres as separate in how they impact children and youth. Additionally, the framework draws on recent management theories. Ansell and Gash (2007) define the conditions necessary for collaborative governance. Kania and Kramer's (2011) theory of collective impact outlines the conditions for effective collaboration for positive, community change. Heifeitz, et al.'s (2009) theory of adaptive leadership helps frame the challenges Heifeitz, et al. theorize about the traits that leaders need to have to address the adaptive challenges. Although this is not a critical study, elements of critical pedagogy are also included, especially when considering whether stakeholders are authentically engaged. The definition of authenticity for the purposes of this study draws on Friere's (1993) work on helping those who have been historically disempowered to reflect on their own needs and experience in order to truly represent their interests. Following is additional information on theories from the field of education that provide the core framework for the research.

\section{Defining Multiple Stakeholder Engagement}

The few researchers that do focus on multiple stakeholder engagement in schools tend to consider the stakeholder holder groups as school, family, and community (Comer, 2004; Epstein, 2011). Teachers and parents are typically included (Comer, 2004; Epstein, 2011). Comer (2006) most explicitly includes school support staff, such as guidance 
counselors and school social workers, as key school members to engage based on their knowledge of child development. However, "community" tends to be poorly defined (Epstein, 2011). Students are typically not included as a stakeholder group (Epstein, 2011). Moreover, from a review of the research, educational researchers are also not typically referenced, nor are businesses and nonprofits (Comer, 2004; Epstein, 2011). These omissions represent a gap in the research on multiple stakeholder engagement that this study addresses.

\section{Defining Authentic Engagement}

For the purposes of this study, authentic engagement is defined by borrowing from Freire (1993) and Giroux (2011). The assumption is that if engagement is authentic, the participants will be educated about the larger systems at work, be aware of their individual needs, and know how these things connect. They will then be empowered to participate and have agency in the change process.

Theories from the Field of Education

\section{Comer's Whole Child Approach and the Comer School Development Program}

James Comer has focused on a child development approach that recognizes that children live in the context of schools, families, and communities and that multiple stakeholders need to be part of the conversation in order to effect positive change (Comer, 1994, 2006). Comer, like Epstein, began his work with a narrow definition of stakeholders, including primarily a range of school personnel with child development expertise, such as social workers and guidance counselors. (Comer, 1994, 2006). Over time, Comer recognized that while this approach improved school climate, it did not address school achievement. This, he found, required the engagement of a broader group 
of stakeholders, including those outside the immediate school community (Brown University, 2013). His model, the Comer Process, now part of the Comer School Development Program at the Yale School of Medicine Child Study Center, focuses on establishing a School Development Program (SDP) with the following guiding principles:

1. that the group will come to consensus through collaboration to address school improvement issues;

2. that this will be done in a "no fault" atmosphere where the focus is not on blame, but rather on solutions (Comer, 2004, p. 24);

3. establishment of a Parent Team that "involves parents at all levels of school activity;"

4. establishment of a School Planning and Management Team that "plans and coordinates school activities;"

5. and establishment of a Student and Staff Support Team that "addresses school wide prevention issues" and "manages individual student cases" (Comer, 2009, p. 19).

Comer's model of the student and staff support team places a unique focus on school climate and child development. These three teams all come together to create comprehensive school plans that address "curriculum, instruction, and assessment; social and academic climate goals; and sharing of information between school and community" (Comer, 2009, p. 19). The model utilizes assessment and modification, as well as staff development (Comer, 2009). Comer's model is unique in that it focuses heavily on improving school climate and individual child interventions informed by an understanding of child development. Like Epstein's model, described below, Comer's 
model does not clearly identify "community" stakeholders, though there are strong decision-making structures where different stakeholders could be included. The focus on meeting the needs of individual students provides some student voice, however this model also lacks a clear role for youth engagement in decision-making. Comer (1996) indicates he was heavily influenced by research in the field of child development in developing his initial theories and then changed his approach over time to include the community, as his research over time identified the value of that inclusion. Overlapping Spheres of Influence and the National Network of Partnership Schools

Joyce Epstein coined the term and outlined the theory of "overlapping spheres of influence" (2011, p. 29) to highlight the important overlap between home, school, and community (Epstein, 2011). Epstein began her work focused primarily on parent engagement in schools and expanded her view of engagement in recent years to include the broad category of “community.” Esptein's (2011) theory of overlapping spheres of influence posits that the "boundaries of home, school, and community are permeable" (p. 69). Her school improvement model evolved into the National Network of Partnership Schools at John Hopkins University (National Network of Partnership Schools, 2013). As of this writing, over 800 schools have adopted Epstein's approach to multiple stakeholder engagement, facilitated by the National Network of Partnership Schools, which includes the development of Action Teams that focus on a set of six core activities:

1. "Parenting: Assist families with parenting skills and setting home conditions to support children as students. Also, assist schools to better understand families.

2. Communicating: Conduct effective communications from school-to-home and from home-to-school about school programs and student progress. 
3. Volunteering: Organize volunteers and audiences to support the school and students. Provide volunteer opportunities in various locations and at various times.

4. Learning at Home: Involve families with their children on homework and other curriculum-related activities and decisions.

5. Decision Making: Include families as participants in school decisions, and develop parent leaders and representatives.

6. Collaborating with the Community: Coordinate resources and services from the community for families, students, and the school, and provide services to the community" (National Network of Partnership Schools, 2013)

Epstein's model is unique not only in the focus on parent and community engagement with schools but also in the support needed to make that a reality. However, it lacks a clear definition of community for the purposes of understanding who, specifically, outside of school staff and parents, should be involved in decision-making. Epstein (2011) indicates that she was influenced by early sociological theory that focused on organizational success in the context of operating independently and the contradictions she found to that approach as she conducted her own research in the field.

Following is a theory of social change from the nonprofit sector that also informed this study.

\section{Collective Impact}

Many sociologists, social philosophers, anthropologists, and nonprofit researchers specifically identify the need for broad community engagement to achieve social change (Feinstein, 2011; Kania \& Kramer, 2011; Kristonis, 2004). In the nonprofit sector, John 
Kania and Jeffrey Kramer's (2011) seminal article, "Collective Impact," based on their research of successful social change efforts, states, "Large-scale social change requires broad cross-sector coordination, yet the social sector remains focused on the isolated intervention of individual organizations" (p. 1). In their follow-up article, "Channeling Change: Making Collective Impact Work," they state "Coordinating large groups in a collective impact initiative takes time and resources, and too often, the expectation that collaboration can occur without a supporting infrastructure is one of the most frequent reasons why it fails" (Hanley, Brown, Kania \& Kramer, 2011, p. 13). Their model focuses on the need for multiple stakeholders to have a common vision, common goals, common measures, and access to research and understanding that enables decisionmaking that results in the desired change. It also calls for strong leadership and resourcing of these efforts.

In the literature review I also looked at theories of organizational change, focused both on schools and in the for-profit sector, to further enhance my research tool development and theoretical propositions.

\section{Organization Change Management Theories}

Modern management theories and recent research into organizational change highlight the importance of participatory environments in effective decision-making within institutions (Heifetz, Grashow, Linsky, 2009; Owen \& Valenksy, 2011; Shein, 2010). Management research suggests that the engagement of outsiders can help to affect positive change by bringing fresh, new ideas (Schein, 2010). Much of the current theory and research on effective management styles and sustainable leadership is focused on 
having leaders facilitate the engagement of others in goal setting and decision-making (Heifetz, et al., 2009, Owen \& Valensky, 2011).

Another modern management theory, which is less well known, but which I felt bridged critical pedagogy and modern management theory is the theory of collaborative governance.

\section{Collaborative Governance}

Ashnell and Alison (2011) have put forward a theory of collaborative governance that outlines key elements of success in collaborative governance efforts. They first define collaborative governance as "A governing arrangement where one or more public agencies directly engage non-state stakeholders in a collective decision-making process that is formal, consensus oriented, and deliberative and that aims to implement public policy or manage public programs or assets" (p. 544). The eight key elements that they identify for effective collaborative governance are:

1. stakeholders participating in all elements of the decision making process,

2. addressing power and resource imbalances,

3. taking a formal approach,

4. ensuring clear ground rules and transparency,

5. ensuring the presence of facilitative leadership,

6. ensuring broad participation is not simply tolerated but actively sought,

7. ensuring the process is consensus oriented (even if cannot always be achieved in practice),

8. and putting the focus on public policies and key issues. 
Adaptive Change Theory is another modern management approach that ties together authentic engagement and management of groups in organizations.

\section{Adaptive Change Theory}

The theory of adaptive change expounds the belief that in order to tackle difficult problems and achieve positive social change, groups of people must be effectively mobilized (Heifetz, et al., 2009). This theory draws on biology and evolution and looks at how nature forms new combinations and variations to enable an organism or a system to thrive or adapt. A key element of this theory is the appreciation of the importance of diversity in achieving a positive improvement in a system (Heifetz, et al. 2009). Adaptive change theory challenges the notion of broken systems and instead looks at systems as evolving. The theory acknowledges that there are inherent trade-offs, however, whenever a system changes, and that will be difficult for people to accept (Heifetz, et al., 2009). Adaptive change theory takes this resistance to change into account and makes the distinction between leadership and authority. Heifetz, et al. (2009) posit that effective leaders recognize that their power does not necessarily come from their authority but from their ability to mobilize people. This is defined as adaptive leadership.

Another important lens applied to this study and used in the development of the interview, observation, and analysis tools is critical pedagogy.

\section{Critical Pedagogy}

Proponents of critical pedagogy have made the case for engaging a broader range of stakeholders and for a deeper approach to participatory decision-making that puts leaders in a facilitation role, supporting those for whom the change is intended, rather 
than in a role of power. Freire's (1993) and Giroux's (2011) approach to first acknowledging and then educating and engaging oppressed groups in a way that enables them to participate meaningfully in change, still provides an important lens through which to analyze the effectiveness of participatory decision-making in schools. One need not be a neo-Marxist, as Freire and Giroux are, to appreciate the value of this kind of authentic engagement, rather than false forms of engagement that represent attempts by leadership only to solicit "buy in" from multiple stakeholder groups rather than to truly empower them to participate in decision-making (Owens \& Valensky, 2011).

Application of critical pedagogy to this study is important because while many public schools do a very admirable job of fulfilling their role of preparing the learner to participate productively in society and become a more fully realized human being, there are many learners who still fall through the cracks (Brantlinger, 2003; Kozol, 1991; Noguera, 2009).

In addition to researching models and theories for multiple stakeholder engagement in decision-making, it was critically important at the outset of this study to identify research on improved student outcomes as a result of multiple stakeholder engagement.

Improved Student Outcomes as a Result of Multiple Stakeholder Engagement There is significant research that highlights the value of multiple stakeholder engagement in decision-making in schools (Bryk, 2002; Bryk, Sebring, Allensworth, Luppeascu \& Easton, 2010; Cook, Murphy \& Hunt, 2000; Henderson \& Mapp, 2002; Epstein 2005; Malloy \& Rayle, 2000; Review of Educational Research, 2013; Sanders 
1996,1998; Sheldon 2003, 2010; Sheldon \& Epstein 2002,2005). There are also robust evidenced-based models of school, parent, and community engagement focused on school improvement. The first, the Comer Process, developed by James Comer (Comer, 2009; Cook, Habib, Phillips, Settersten, Shagle \& Degirmencioglu, 1999; Cook, Murphy \& Hunt, 2000; Henderson \& Mapp, 2002, Malloy \& Rayle, 2000), is a model shown to have positive effects on school climate and overall student academic achievement. The second, the National Partnership Schools model developed by Joyce Epstein (Epstein 2005, Galindo \& Sheldon 2011; Gordon \& Seashore 2009; Heck \& Hallinger 2009; Henderson \& Mapp, 2002; Martin, Fergus \& Noguero 2010; Sanders, 1996;1998; Sheldon 2003; 2010; Sheldon \& Epstein 2002, 2005; Sanders, 2006; Sitton Hays, 2011), offers another model for positively impacting student academic achievement as well as improving school safety.

Researchers have found that schools that engage a wide range of stakeholders can be successful in achieving improvements in school climate and academic achievement (Cook, Murphy \& Hunt, 2000; Epstein, 2005; Henderson \& Mapp, 2002; Malloy \& Rayle, 2000; Owens \& Valensky, 2011; Sanders 1996; Sanders 1998; Sheldon 2003, 2010; Sheldon \& Epstein 2002, 2005).

School improvement teams, which can be known by many different names, including school leadership teams, are becoming common in schools across the country in response to No Child Left Behind and Race to the Top requirements from the federal government that increased federal government requirements on multiple stakeholder engagement (U.S. Department of Education, 2001, 2009, 2014). 
I began the literature review by looking for research into school improvement teams. From an exhaustive search in educational journals using EBSCOhost and JSTOR, I could find no specific research into the structure or effectiveness of groups specifically referred to as school improvement teams or school leadership teams. From an online review of school improvement team mission statements and handbooks at a sample of thirty school improvement team mission statements throughout the United States, a common theme was a team-based, meeting-driven approach to engaging multiple stakeholders in school improvement (Barnes, 2004; Commonwealth of Virginia Department of Education; Louisiana Department of Education, 2010; Massachusetts Department of Secondary and Elementary Education, 2014; Michigan Legislature, 2014; North Carolina General Assembly 2014; Oklahoma State Department of Education, 2014; Pennsylvania State Education Association, 2007; Rhode Island General Assembly, 2011; West Virginia Department of Education, 2013). Despite the proliferation of these efforts, I was able to find very little research on school improvement teams or rich descriptions of how they function. There is limited and mixed research on whether organic, "grassroots" school, family, and community partnerships, i.e., those that do not follow a specific research-based model, are successful (Borman, 2000). A drawback the research finds generally with grassroots reform efforts is that they are likely to take much more time as a result of learning while doing (Borman, 2000). However, one benefit of a grassroots approach is that there may be much higher teacher morale than with prepackaged reform efforts or efforts led by an outside entity (Borman, 2000). 
From the research that does exist, I was able to glean five key factors for success in engaging multiple stakeholders in decision-making in public schools, regardless of the model used.

Elements of Successful School, Parent, and Community Partnerships Regardless of the model used, research points to five key factors involved in multiple stakeholder engagement efforts that result in improvements in school climate and/or academic achievement.

- It takes at least three to four years for meaningful change to take place (Martin, Fergus, \& Noguero, 2010, Sanders, Sheldon, \& Epstein, J. 2005).

- There is a clear need for formality and structure (Martin, Fergus, \& Noguero 2010; Sanders 2005; Sanders, 2006).

- Strong leadership is required, in particular, school principals who value and prioritize parent, school, and community partnerships and who possess skill in developing these relationships (Epstein, Galindo \& Sheldon 2011; Gordon \& Seashore 2009; Heck and Hallinger 2009; Martin, Fergus \& Noguero 2010; Sanders, 2006; Sitton Hays, 2011).

- Partnership must be actual, where the voices of all groups are truly included in decision-making processes (Henderson \& Mapp, 2002; Hope, 2012; Sitton Hays, 2011; Sanders, 1996; Sanders, 1998; Sanders, 2006; Sheldon, 2010; Sheldon, 2003; Sheldon \& Epstein, 2002; Sheldon \& Epstein, 2005; Epstein, 2005).

- Student-centered focus on improvements in both school climate and academic achievement is essential (Cook, Habib, Phillips, Settersten, Shagle \& 
Degirmencioglu, 1999; Martin, Fergus \& Noguero 2010; Sanders, 2006; Sitton Hays, 2011)

\section{Models for Successful School, Parent and Community Partners}

The most robust research on a particular model of school, family, and community partnership has been conducted on Joyce Epstein's National Network of Partnership Schools model. There is significant quantitative and qualitative research showing the effectiveness of this model on math achievement, standardized tests, attendance, behavior, and safety. While there is still a need for additional research, results from studies to date have shown success with a wide variety of school types and with a variety of student populations (Epstein 2005, Henderson \& Mapp, 2002; Sanders 1996,1998; Sheldon 2003; 2010; Sheldon \& Epstein 2002, 2005). One critic of this model found through qualitative research, that the engagement of parents was not always fully authentic (as I have described in the definition on page 11) and that parents and schools did not always share a common language and equal power for engaging in school improvement (Stelmach, 2004; 2007).

The other model that has been studied and found to be successful, though the research does not appear to be extensive, is on the Comer Process (Comer 1996). Research on the early model that focused on school climate showed that school climate improved but academic achievement remained flat (Cook, et al, 1999). Improvements to the model resulted in changes in both school climate and academic achievement. This model has been able to achieve positive changes in school climate and academic achievement in schools with a population of students that is primarily African-American 
and with low socio-economic status (Cook, Murphy \& Hunt, 2000, Henderson \& Mapp, 2002, Malloy \& Rayle, 2000).

Organic Approaches to School, Parent and Community Partnerships There is mixed research on the success of schools that approach multiple stakeholder engagement on their own, without a clear model for engagement in place, such as the school improvement teams I studied (Borman, 2000). It would seem from the research cited above that the best approach would be to begin with an existing researchbased model such as the Comer Process or the Partnership Schools model or to ensure that the key characteristics of what I will call "successful organic efforts" are included: strong, school principal leadership with the ability to authentically and effectively engage stakeholders; a formal structure; appropriate time and resources; and a simultaneous student-centered focus on improving both school climate and academic achievement. Research into models that did not have formal structures has shown a lack of success (Gordon and Seashore, 2009; Miller and Rowan, 2006). The drawback to informal organic improvement efforts that seek to engage multiple stakeholders is that they must reinvent the wheel, rather than building on what others have learned through implementation and research. Another drawback of unplanned organic reform efforts is that they are likely to take much more time as a result of this learning while doing (Borman 2000). However, the benefit of an organic, grassroots approach is that there may be much higher teacher morale than with pre-packaged reform efforts or efforts led by an outside entity (Borman, 2000). 
As a result of limited research in this area there were some insights from the research that did not fall into their own research category because they did not have a significant number of studies behind them. However, the research was still relevant to my study and I have included those findings below.

- High schools typically need more support than elementary and middle schools to engage parents. This is not because of an inherent challenge in high schools, but rather because there is a history of less engagement (Sanders, 1998, Sanders and Simon, 2002).

- The research into school, family, and community partnerships that have been effective in improving student achievement has been done primarily with student populations that are low-achieving. The issue of low achievement provides a strong impetus for schools seeking to serve these populations to take this collaborative approach to change.

- Most of the research focuses on family engagement and the engagement of teachers and school personnel and to a lesser extent on broader community engagement (including universities, businesses, and nonprofits), though this research is occurring and has become more common in the past few years.

- In rare circumstances communities have initiated the engagement and have been successful (Arriaza, 2004). Typically, school, family, and community partnerships are initiated at the district or school level.

While there is still a need for research in the education field to more fully understand the impact and promising practices of multiple stakeholder engagement, it is worthwhile to note that an interest in multiple stakeholder engagement as a way to meet 
organization goals is mirrored in both the nonprofit sector and the for-profit sector.

Theory and research on this approach are growing independently in these sectors and are coming to similar conclusions on promising practices for success, as outlined throughout this literature review (Ashnell and Alison, 2007; Hanley, Brown, Kania and Kramer 2011; Denis, Lamothe and Langley, 2001; Heifeitz, Grashow \& Linsky, 2009; Wenger, McDermott, Snyder, 2002). Still, compared to other fields of educational study, there is relatively little research on multiple stakeholder engagement in decision-making in public education, such as the school improvement teams studied for this project. The focus of this literature review was primarily on those studies that do take into account the engagement of multiple stakeholders, as it is a much different thing than when research only looks at how a school engages one particular type of stakeholder in decisionmaking. Though it may be possible to draw some insights from areas of research where the engagement of specific stakeholder groups has been studied in isolation from other groups, I have chosen to focus on research that looks at multiple stakeholder engagement in decision-making, as it provides a more complex understanding, the nuances of which would not be captured if looking simply at a school's engagement of one group at a time, such as teachers alone or parents alone.

The focus of the research study is on how two high schools attempted to engage multiple stakeholders in decision-making on school improvement teams, as required by legislation, with emphasis on who the schools included, how they engaged them, and why they engaged these stakeholders in the ways that they did. 
Gaps in the Research

The majority of the literature on stakeholder engagement in decision-making tends to be broken up by stakeholder group. There are many studies that have shown the value of parent engagement and teacher engagement in decision-making in education. However, few studies look at stakeholder engagement holistically, including the broad range of other stakeholders, such as businesses and nonprofits; engagement of community is not well defined, if at all (Epstein, 2011). In addition, student voice has also largely been left out of the research into multiple stakeholder engagement (Epstein, 2011; Hope, 2012). However, educational researchers are beginning to appreciate the value of including youth voices (American Educational Research Association, 2012; Corcoran, 2012; Rogers, 2012). It is important to note that research also points to the inherent conflicts in multiple stakeholder engagement in education, such as the difficulty of wedding various perspectives, and mediating power relationships and educational structuring (Owens \& Valensky, 2011). However, these challenges have not been deeply described in the research. It hoped that this research study will help to illuminate these gaps. 


\section{CHAPTER 3 - METHODOLOGY}

The focus of the research study was on how two high schools engaged multiple stakeholders in decision-making on state-mandated school improvement teams, with emphasis on who the schools included, how they engaged them, and why they engaged these stakeholders in the ways they did.

The hope of this researcher is that this study will lead to the identification of factors influencing stronger democratic partnerships, including multiple stakeholders in decision-making in public schools.

\section{Procedures}

An analytical, qualitative, multiple-case study method with a focus on cross-case analysis was used in this research study, drawing on Yin (2009), Stake (2006), Merriam (2009), and Patton (2002). This research and analysis is heuristic in that it seeks to help the researcher and the reader understand the phenomenon under study through intensive description (Merriam, 2006). A combination of interviews, observations, and a review of documents were used to describe the efforts of school improvement teams to enable the participation of multiple stakeholders in decision-making at two public high schools. Other multiple stakeholder engagement efforts underway in the schools were also identified during interviews, though these efforts were not observed directly.

Multiple case study method has a distinct advantage over other qualitative or quantitative approaches because it allows cross-case themes to emerge, shaped by the overall theoretical framework (Merriam, 2009; Stake, 2006; Yin, 2009). Particular attention was paid in the analysis to themes that emerged in both school environments 
studied. The research took take place over the course of one full school year from September 2014 through June 2015.

\section{Sampling}

Sampling was purposeful. The two high schools that were chosen for the case studies had active school improvement teams, meaning they had plans to meet during the year (Stake, 2006). Schools were identified from a Northeast state that has a state law mandating school improvement teams. Schools were also chosen based on whether active multiple stakeholder engagement existed so that rich case study analyses could be conducted. This was identified based on researcher conversations with superintendents, and also with local community groups and other school personnel, prior to the research that confirmed a commitment to multiple stakeholder engagement. Both schools were chosen from the same Northeast state but were located in different cities in that state. One charter public high school (School 1) and one traditional public high school (School 2) with different curricular approaches were chosen for the study as a way to increase variability. Specific selection criteria included:

- schools that had an established school improvement team;

- schools that had leaders who had verbally expressed a commitment to multiple stakeholder engagement;

- schools demonstrating extensive efforts toward multiple stakeholder engagement, as confirmed by other local community groups and school personnel;

- and schools that had a racial, ethnic, and socio-economically diverse student population. 
The focus on variability in terms of school types (charter versus traditional, different curricular approaches, and different cities and school districts) comes from the research of Merriam (2006) and Stake (2009) who highlight variability as important to validity in multiple case studies. Schools chosen in the same state ensured that the state policy requiring engagement would be the same in both schools. This mandate requires documentation of the inclusion of parents, youth and other community members on the team and requires that all stakeholders have input into the development and review of the school improvement plan; the document is required by the state's department of education.

The choice to study schools with diverse populations mirrors the research into parent, school, community partnerships, which focuses on diverse schools where the underachievement of different populations is a goal for improvement.

The theoretical frameworks and researcher perspective guided an examination of whether a wide range of stakeholders was included in decision-making, including parents/caregivers, teachers, students, businesses, guidance counselors, social workers, educational researchers, nonprofits, state agencies, and students.

Participants: School improvement team members were the only participants interviewed, using a pre-designed protocol (See Appendix B). At School 1, all six high school members of the school improvement team were interviewed. At School 2, six of the eight high school-based, school improvement team members were interviewed. One was unable to be interviewed because he was out on medical leave for the majority of the study. The other member abstained without stating why. 
Observations: I observed all of the 2014-2015 school year school improvement team meetings at each school. This included ten meetings at School 1 and seven meetings at School 2.

Document Analysis: I reviewed the state law requiring school improvement teams and I was given access to all agendas and handouts for school improvement team meetings at each school, which I reviewed as part of the analysis and triangulated with interviews and observations. I also had access to the publicly available teachers' union contract at School 2, which I also reviewed and triangulated with other data from School 2.

Given the high variation between the two cases chosen, the cross-case analysis was intended to contribute to the field by providing information on how schools engage multiple stakeholders in decision-making in urban, socio-economically, racially, and ethnically diverse school environments, with a focus on how this is done under legislated engagement mandates.

A commitment by the school superintendents to engage diverse stakeholders in the high school, and a number of community partnerships, together with student and parent engagement was common to both schools. This commitment was stated in informal conversations with the superintendents during the process of identifying high schools for the study. The commitment was also confirmed in informal conversations with colleagues in the field and in the schools prior to choosing the schools for participation in the study.

My research focused on a very specific construct in the schools - the school improvement team. School improvement teams are mandated by state law in the state 
where the schools that I studied operate. The state law is titled the School Improvement Team Act. It was introduced in 1995 and includes the following statement. (A citation is withheld here to protect the identity of the schools).

Each school improvement team shall be composed of the principal and an appropriately balanced number of teachers, education support employees, students, parents, and other business and community citizens who are representative of the ethnic, racial, and economic community served by the school, provided that vocational-technical center and high school schoolimprovement teams shall include students, and middle and junior high school school-improvement teams may include students. Members representing teachers, education support employees, students, and parents shall be selected by their peer groups at the school in a fair and equitable manner...

(2) Business and other community members shall be selected by the school according to a procedure established by the school board. The school board shall review the membership composition of each school improvement team. Should the school board determine that the membership elected by the school is not representative of the ethnic, racial, and economic community served by the school, the board shall appoint additional members to achieve proper representation. For the purposes of school improvement teams, the term "teacher" includes classroom teachers, certified student services personnel, and media specialists. For purposes of this subsection, "education support employee" means any person employed by a school who is not defined as instructional or administrative personnel pursuant to law and 
whose duties require twenty (20) or more hours in each normal working week. (b) The school board may establish a district school improvement team representative of the district and composed of teachers, students, parents, and other citizens or a district school improvement team, which may be comprised of representatives of each school improvement team.

Duties of the school improvement teams. - Each school improvement team shall perform any functions that are prescribed by regulations of the school board or school committee; no school improvement team shall have any of the powers and duties now reserved by law to the school board. Each school improvement team shall assist in the preparation and evaluation of the school improvement plans and shall provide any assistance that the principal may request in preparing the school's annual budget and plan as required by law.

Both schools implemented these teams through a traditional meeting structure, around a conference table, with an agenda, during or just after the completion of the school day. However, each school's education model was very different, and each school's approach to the school improvement team varied greatly in the composition of team members and process of engagement. Nonetheless, many findings relative to the propositions were shared across both cases. These findings are likely to shed some light on shared strengths and challenges schools may face in implementing a school improvement team of the type described in the legislation.

Great care was taken in the presentation of this analysis to preserve the anonymity of the schools so school- or person-specific details are not included. These details do not 
obscure the findings or the data. All quotes are verbatim, except in those cases where terminology specific to that school or names of individuals or titles are paraphrased or changed to ensure anonymity. The details removed do not result in a loss to the reader of any pertinent information or understanding. For example, specific state requirements or state tests that were discussed at school improvement team meetings were not formally identified. The specific name of the state test or state agency is not identified. Also, in both cases the team meetings were referenced as "school improvement teams" although each school gave their team a unique name. The superintendent at each school clearly identified the team studied as the group within the school that was meeting the state regulation that requires a school improvement team. Therefore, the proxy use of "school improvement team" as a name to describe each team was viewed as appropriate in this study.

The two schools chosen for study were chosen for maximum variability. Although there were many specific findings particular to each case, those are not included because of the intent to focus on themes that were found across cases. Following is a brief description of each of the schools studied.

School 1: School 1 is a nonprofit, charter high school with a unique education delivery model that is focused on personalized learning and internships in the community. The curriculum is very different from the traditional public school curriculum in the state and district in which it operates. The curriculum is focused on personalized learning and learning through internships in the community. The school improvement team in School 1 was very homogenous in that it was made up entirely of administrators, and there were a total of six team members. The team members were all 
chosen by the superintendent for participation. The team met every other week throughout the school year. They missed only two meetings due to scheduling conflicts with other school activities. I observed all of these meetings and also interviewed all six team members.

School 2: School 2 is a more traditional high school with a standard high school curriculum. The school improvement team in School 2 was broken into three layers. At the top layer was the full district team made up of elementary, middle, and high school administrators, teachers, and faculty. Teachers and faculty were elected by their peers to their role. It must be noted that the teachers' union had a strong position in the school relative to the school improvement team. The district's contract with the teacher's union added stipulations related to the school improvement team stated as follows:

The [secondary school improvement team] shall be composed of the following members:

1. Six (6) teachers from the Secondary Schools to be elected by the faculty of the schools. There shall be at least two teachers from each Secondary School Building who received the most votes cast by Secondary School teachers elected to the council. The balance of teachers may be from any Secondary School. 2. Two (2) teachers from the Secondary Schools to be appointed by the CFTU.

3. One(1) non-certified school employee elected by members of AFSCME Council94.

4. Two (2) Administrators appointed by the Superintendent and/or Board of Trustees.

5. One (1) parent to be elected at a parent meeting to be held in the month of 
September.

6. The Superintendent of Schools or her/his designee.

7. The High School Student Council President.

8. One (I) local business leader or other community member appointed by the District Management Council in accordance with applicable Board of Trustees policy

The teacher's union president attended all district level meetings but was not an official member of the team. The district level group met once at the beginning of the year, once in the middle of the year, and once at the end of the year. The middle layer was focused just on the middle and high school and was made up of middle and high school teachers and administrators. The team met only twice throughout the entire school year, with no planned schedule and many cancelled meetings. The second meeting, held in October, was cancelled because the group felt that they had already convened in September once, as had the full district team, and they agreed that was sufficient for that timeframe. The third and fourth meetings were cancelled at the last minute, and the reason was unknown at that point. Later conversations with the school principal revealed that the leadership did not find these meetings very helpful due to involvement of union representatives who wanted to ensure that anything negotiated under union contract would not be discussed. Unlike School 1, School 2 teachers were paid to participate. Leadership stated in interviews that they felt this put a strain on the budget. One final meeting of the middle layer was held, for a total of two meetings at this level. The final layer was at the high school level, which was where my research was focused. This team, made up of seven members, was only supposed to be called together as needed and only 
met twice in the last two months of the school year.

I observed all seven meetings at all layers in School 2 throughout the 2014-2015 school year even though my main focus was on the high school. I also interviewed six team members associated with the high school-based team, which were inclusive of all but one of the site-based members, one who was out on sick leave and one who abstained without giving a reason.

\section{Confidentiality}

Participants consented to participation in the study, and all transcripts of the conversations were, and continue to be, kept in a password-protected computer. They will be destroyed three years after study completion. No minors were interviewed. Careful consideration has been made to keep the real names of participating schools and individuals interviewed or observed confidential, and the names used in the findings are fictitious. Actual names will not be published at any stage and careful efforts have been made to conceal identities in the case descriptions. The proposed study was reviewed by the Institutional Review Board and deemed to comply, and actual implementation followed all research protocols.

Data Collection and Activity for Interviews, Observations, Document Review During the 2014-2015 academic school year data were collected by observing school improvement team meetings at two different high schools, reviewing documents connected to school improvement team work and interviewing select participants. Tools were created for this purpose based on the primary research questions and the overall theoretical framework (see Appendices C and D) (Stake, 2006; Yin, 2009). 
Interviews

Prior to interviewing the participants at each school, attendance at two school improvement team meetings provided context for conducting the interviews (Merriam, 2009). Interviews of the individual members of the school improvement team, which were approximately one hour in length, were conducted between observations. The interviews were semi-structured and followed the protocol outlined in Appendix B. All interviews took place in person. It appeared that all research questions were answered in the first interview to the best ability of study participants so I deemed no further interviews were required. At the start of each interview, an explanation of the goals of the research was conveyed. Each interviewee was asked to speak broadly about their experiences before being asked specific questions in the interview protocol that related to school improvement team processes and procedures (see Appendix B). These responses were considered first in the analysis because they represent the participants' thoughts without specific prompting questions. Interviewees asked that observed sessions and interviews not be taped, though they agreed to typed written notes. I was able to type responses and was able to record most responses verbatim. Interview questions were asked as they were written (see Appendix B) to ensure maximum reliability. Brief clarification was given when participants requested it. Clarifying questions asked by the researcher were kept to a minimum and noted when asked.

\section{Observations}

I typed notes during observations of all team meetings. I also was not allowed to record observations; however, most discussions were typed verbatim in meetings as well. 
When participants nodded their heads in agreement or gave other signs that they were in agreement on particular items discussed that would not have otherwise showed up in the transcript I did some pre-coding during observations in order to capture this.

Additionally, when team members joked with one another and when there was conviviality or tension observed through body language that might not have been easily captured in the transcript, these were also noted. I did not capture the details of conversations of a personal nature at the beginning of meetings but noted the rapport between team members when this occurred. The interview findings were triangulated with interview responses and documents provided at meetings as well as general school documents and legal documents directly pertaining to school improvement team processes.

Document Review

A list of documents reviewed included school mission statements and strategic plans; state laws and regulations related to the school improvement teams; minutes from school improvement team meetings; minutes from related group meetings; and teachers' union contracts.

\section{Tools for Data Collection and Analysis}

The seven questions below, identified at the outset of this study, drove research tool development and analysis. Following are the key questions that framed this study and were at the forefront of the tools developed:

1. Who are the stakeholders that are engaged in school improvement teams, and why were they chosen or asked to participate?

2. In what ways, if any, are the stakeholders engaged in school improvement teams? 
3. What types of decisions do the stakeholders engage in? What types of decisions are they not engaged in?

4. In what ways, if any, do the facilitators support the process of multiple stakeholder engagement in school improvement teams?

5. What are the strengths and difficulties shared by schools attempting multiplestakeholder engagement through school improvement teams?

6. Are there other multiple stakeholder engagement efforts connected to school improvement teams?

7. Is there evidence of authentic engagement (Friere, 1993), adaptive leadership (Heifetz, et al, 2009), and/or collaborative governance (Ansell \& Gash, 2007; Kania \& Kramer, 2011)?

The following tools were developed (see Appendices B, C, D, E) to support my proposed research questions and align with my theoretical framework. These tools helped to identify cross-case themes that influenced engagement and questions for further study.

Appendix A: Consent Form for Research: A research consent form was developed (Appendix A), which all participants signed.

Appendix B: Interview Tools: This interview tool was developed with questions for members of the school improvement team and key decision makers (Appendix B). Appendix C: Table for Tracking Propositions and Appendix D: Stakeholder Tracking Form: It was assumed that answers to some questions would be revealed through analysis and observation, creating the need for specific research tools that were developed for this purpose (Appendices C and D) (Yin, 2009). Appendix C was used after observations to track what was observed and was compared with coding of 
observations. Observation and interview codes were also mapped to the questions in Appendix C. Appendix D was used to track comments of members of the team and other stakeholders, relative to the propositions that were discussed throughout interviews and observations. The tool also captured the level of engagement of these stakeholders - such as whether they were actually present at the school improvement team meetings, or whether their voice and ideas were brought to the table in other ways.

Appendix E: Form for Tracking Codes: A tool was also developed to track codes as they emerged and to further refine codes as data were triangulated across data sources and cases.

Interview questions (Appendix B), observation tools (Appendix C), and proposition tracking forms (Appendix D) were structured to align with gaining insight into these original questions and were aligned to the theoretical framework. I used Appendix $\mathrm{C}$ at the end of each observation to identify whether any of the questions in the tool had been addressed through my observation of that meeting. During and after each observation Appendix D was also used to track the individuals participating in the meeting and their level of participation. I also used Appendix D to track stakeholders whose ideas or feedback was discussed at the meeting and or noted in interviews, even if they were not present at the school improvement team meetings, I noted that they were identified as stakeholders in the school not present at the meetings.

\section{Data Analysis}

Interviews were coded for repetitive patterns to identify key themes and to focus on "essence capturing" (Saldana, 2013), meaning that codes were heuristic, coding was done cyclically and not just for labeling but also for linking. Coding was done more than 
once in order to code for patterns to see if things were happening in similarly predictable ways across interviews within a case, across interviews and observations within a case, and across cases. Codes were "in vivo" where possible (Huberman, Miles \& Saldana, 2014; Saldana, 2013). The theoretical framework and proposed research questions remained in the foreground when coding (Miles, Huberman \& Saldana, 2014; Saldana, 2013). Coding was done directly from transcribed notes and the key codes identified were tracked using the form in Appendix E. Interviews were also pre-coded. During interviews, I typed while the interviewee was talking and bolded certain passages or phrases that appeared most germane to the question asked or seemed to represent a theme that I had heard in other interviews (Miles, Huberman \& Saldana, 2014; Saldana, 2013). This was also done during observations.

Analytic memos were used to track the coding methods used and to reflect on key questions in the first half of the year. These memos answered the following questions (Saldana 2013).

1. What are people doing? What are they trying to accomplish? How exactly do they do this? What specific means or strategies do they use?

2. How do members talk about, characterize, and understand what is going on? What assumptions are they making?

3. What seems to be going on?

4. What did my notes reveal, and why did I include them?

5. What surprised me? (to track assumptions),

6. What intrigued me? (to track positionality), 
7. What disturbed me? (to track tensions within my value, attitude and belief systems).

The analytic memos were completed right after the interviews and observations, and all were completed a few months prior to coding and analysis so that I was able to review my assumptions from the analytic memos and reflect on whether my coding choices may have been linked to my initial assumptions. I did not find any clear evidence of this. Cross-case analysis was very helpful in adding additional validity as I focused on findings that could be identified in both cases. Attention to triangulation between interviews, observations, and document review also aimed to reduce assumptions.

During my analyses of the interviews, observations, and documents, linkages to previously-identified propositions were made, based on the approaches suggested by Yin (2009) and Stake (2006) (see Appendix C and Appendix D, respectively). The "constant comparative" method, requiring analysis of data and actively comparing it to other analyzed data (Charmaz, 2006), was used. It was assumed that the themes and concepts outside my original theories and constructions would arise, and my research tools gave me the structure for tracking those (Stake, 2006). I used Appendix C and D to track the degree to which each case illuminated the research questions. (Stake, 2006; Yin, 2009) and tracked themes that emerged during coding using Appendix E, which was also developed in advance. Individual case studies were emphasized through the use of these tools, as well as themes that emerged across case studies. Each case was viewed as a finite case that ultimately helped to better define the "quintain," defined as the full complement of cases (Stake, 2006). The purpose of coding the interviews, using tables developed for observations and document analysis, and to document the outcome of the 
coding process, was to allow for a chain of evidence to emerge to support the claims I made (Yin, 2009). Full descriptions of each individual case, inclusive of responses to research questions that were illuminated, as well as the themes that emerged across cases were summarized (Stake 2006). It was assumed that relevant phenomena would be observed that were not considered at the start of the research.

Documents that discussed policy provisions for decision-making and the roles of different stakeholders were consulted to better understand the larger context and inform the observations and interviews analysis.

The focus of final analysis was on the cross-case themes, themes that were identified in both cases and relevant to the original research questions.

\section{Validity and Reliability}

Although the terms validity and reliability are not preferred by all qualitative researchers, Yin (2009) suggests the use of these terms when using multiple case study methods. Additionally, Maxwell's (1992) definitions of validity in qualitative research were also considered. For validity and reliability, the research tools developed were shared with experts in the field of education that represented a broad range of experience (Stake, 2006; Yin, 2009). These experts included faculty members and peers with experience in the education field at the University of Rhode Island's School of Education and Rhode Island College's School of Education. I also addressed validity and reliability by clearly building on my theoretical framework to develop the interview questions and observation and document analysis tools (Stake, 2009). The data were triangulated in order to ensure greater internal validity by comparing different interviewee responses and comparing observations to interviews. Data was also triangulated through discussion of 
findings during the process with experts in the field. This triangulation supported efforts to investigate and test rival explanations (Stake, 2006; Yin, 2009). The interview protocol described was closely followed, and a chain of evidence was developed to increase construct validity. The tools developed in Appendices B, C, D, and E supported construct validity and triangulation (Stake, 2006; Yin, 2009). A case study protocol and database were created to increase reliability, and the steps were operationalized to the greatest extent possible (Yin, 2009). External reliability was improved through generalizing a specific set of results to the larger theoretical framework, and through replication achieved through cross-case themes emerging through multiple case studies (Yin, 2009). However, ultimately, individuals reading the study will find their own meaning. As Merriam (2009) states, "It is the reader, not the researcher, who determines what can apply to his or her context" (p. 51). The findings will be presented in a way that facilitates that interaction with the reader.

\section{Study Limitations}

As with any research study, certain limitations are assumed. For example, how the interview questions were structured, the schools chosen for the study, and the degree to which interviewed individuals felt able to speak openly and honestly and give significantly of their time, all potentially impacted the internal validity of the study. The abstention from the interview process of one of the members of the school improvement team from School 2 represents a limitation. The description of the proposed research study itself may have introduced new thinking to participants, which could have affected subsequent subject interviews and meetings. Also, the fact that only two schools were studied through the limited view of the school improvement team meetings provides a 
limitation. Considerations of preconceived ideas about the importance of multiple stakeholder engagement and my theoretical framework underpinning this study also present a biased view. My limited direct experience in teaching or administration in public high schools could also be a limitation, as I have taught mainly at the college level and I have no teaching expertise at the high school level. Additionally, my previous experience facilitating multiple stakeholder engagement in the nonprofit/public sectors, along with serving on a school improvement team at my child's school during the course of this research, possibly creates a bias in my perspective that multiple stakeholder engagement is important. As with any qualitative study, findings cannot be generalized to other school environments but readers will draw their own meaning, conclusions and ideas from analysis and rich descriptions provided through interview quotations and observation descriptions. A final limitation is that this study did not focus critically on the role of race, ethnicity, and gender, but they are a set of possible factors at both urban schools. 


\section{CHAPTER 4 - FINDINGS}

The goal of this multiple case study was to answer seven key research questions by conducting a cross-case analysis between two schools with active school improvement teams. At times, differences in cases are also identified. In my findings here I include excerpts from interviews, portraits of experiences observed at meetings, as well as an analysis of the connected review of documents that allow the reader to understand richly the team members' perspectives and what I as the researcher saw and heard during observations and interviews.

Before a description of findings is explored, I begin with a description of the schools and their school improvement teams in general:

\section{Brief Description of School 1}

At the time of this study, U.S. Census data and state department of education data identified School 1 as situated in a city of 179,000. Twenty-nine percent of the city households had children living in them, and the median household income in the city was $\$ 26,867$, less than half the median income in the state, which was $\$ 56,523$. Forty percent of children and youth in this city were living below the poverty line. Data indicate that there were 810 students in this public charter high school. Forty-three percent of those students were Hispanic, thirty-seven percent White, thirteen percent African American, five percent multi-racial, one percent Asian, and one percent Native American. These percentages very closely mirrored the overall population of the city. Sixty-eight percent of students in School 1 were eligible for free and reduced lunch. Two percent were receiving English as a second language services, and thirteen percent were receiving 
special education services. Based on standardized testing, approximately one third of students were meeting or exceeding literacy standards in high school, and approximately one quarter were meeting or exceeding math standards. This was on par with the statewide performance levels. The four-year graduation rate was eighty-nine percent. The per pupil spending was nearly $\$ 16,909$.

School 1 was settled on a newly-built campus in a high poverty neighborhood in the city. From my observations, young people seemed to come and go around the school grounds in a manner more typical of a college campus than of a traditional high school. The students appeared engaged in purposeful activity and also appeared happy and respectful. Students have some core courses in this school, primarily focused on math and literacy, along with vocational opportunities with businesses in the community. Each student chooses a field of study, based on specific personal interests, and then pursues that field with the support of an external internship and an internal, school advisor. Students learn in the field from an assigned mentor, design their own projects, and some take college courses at a nearby community college. Class sizes are small and students meet primarily in advisories. The teachers and staff appear to have great pride and belief in this model, which is in stark contrast to a more traditional high school curriculum and climate. Teachers stated that they felt they know their students well and that students supported one another as they pursued their own dreams and passions. The founder of the school was still actively involved at the time of this study. This charter school model has over eighty locations around the country and the world. 
School 1 was chosen because of its commitment to student voice, parent engagement, community involvement, and the involvement of businesses through internships and a business advisory team.

According to the curriculum director, the school improvement team at School 1 has been a standing team that was also able to fulfill the requirement of the state legislation requiring school improvement teams. The curriculum director noted that, as a charter school they always try to balance the state department of education's requirements while remaining true to their model.

Interviews with the superintendent of School 1 revealed that members of the school improvement team were chosen based on who could best support the school principals and ensure that messaging was clear. Members of the team included the superintendent and administrators, representing social work, curriculum, professional development, literacy, and special education. In my first meeting, it was clear that the group members felt very comfortable with one another and most interacted as friends. This was later confirmed during interviews. All relationships, regardless, were very congenial and positive. In coding my observations, I would note many instances of laughter in all meetings and much conversations of a personal nature at the beginning of meetings.

Meetings at School 1 took place in the superintendent's office. It had personal touches including vases of flowers and pictures. Although it was the superintendent's office it did not have a desk, only a conference table. The superintendent stated this was because the superintendent felt the administrative role was to be out in the school meeting with people, not to be behind a desk. 
The team met ten times over the course of the school year as had been planned from the beginning of the year. The meetings were bi-weekly, with the exception of during vacations. Only two meetings were cancelled due to school-wide conflicts. Each meeting would follow the same pattern, with the facilitator and the curriculum director, coming to the meeting with a predetermined agenda relating to key school improvement issues that the team had jointly agreed to address. The agenda and other items related to the discussions, such as reports of student achievement, or documents created as followup to meetings, were available primarily on a Google drive and team members came with their computers to review documents. I was given access to the paper versions of the documents. The Google documents were shared and the facilitator always reminded the group to feel free to edit the agenda in advance of a meeting if they wanted to add an item. The facilitator also took notes on the key decisions and noted any 'next steps' recommended from the meeting; these were shared on the Google drive and discussed at the next meeting if the conversation needed to continue. Over the course of the year, the main focus of the discussions was on improvements in literacy. However, there were many other issues discussed as well that will be outlined in this chapter. It was clear that the team relied on the expertise of individual members, while everyone had the opportunity to provide input and to question. For example, when literacy was discussed, the professional development director would be asked to identify how to address this school-wide, the special education director would share information about how to work with students who had special needs, and the literacy director would offer specialized reading interventions. Additionally, rich conversation would take place in which all team members would share their expertise and understanding of the issue. Regardless of the 
issues discussed, the team grappled at every meeting with difficult school improvement issues together, slowly building toward consensus. This move toward consensus was something I observed in meetings, and also confirmed through my interviews. This will be discussed in with specifics in my more detailed findings in this chapter.

What become immediately apparent during my first few observations of team meetings was that no students, parents, business or community members, or teachers were present, as the school improvement legislation requires.

\section{Brief Description of School 2}

At the time of this study, U.S. Census data and state department of education data identified that School 2 was also located in the center of a high poverty area in a different and smaller city in the same state. The school was situated in a city of 19,000 with thirtynine percent of households having children living in them. The medium household income in the city was $\$ 22,628$, far below the median in the state of $\$ 56,523$. Forty percent of those below the age of eighteen were living below the poverty line. In the high school there were 662 students. Seventy-two percent of students were Hispanic, ten percent White, twelve percent African American, four percent multi-racial, one percent Asian, and one percent Native American. These percentages closely mirror the population of the city, although there is a slightly higher non-Hispanic White population in the city than in the school system. Seventy-two percent of students were eligible for free and reduced lunch. Twenty-nine percent were receiving English as a second language services and twenty-three percent were receiving special education services. Based on standardized testing, approximately one third of students were meeting or exceeding literacy standards in high school and approximately one quarter were meeting 
or exceeding math standards. This was on par with the statewide performance levels. The four-year graduation rate was eighty-one percent. The per pupil spending was nearly $\$ 17,982$.

The school building was a large, older, brick building. Across the street from the school was an abandoned and boarded-up building and many of the other buildings surrounding the school were also poorly kept. The school itself fit into its environment, looking dated, though very large. A banner usually hung in front of the school noting some achievement or event, which, appeared to add some brightness and positivity. The paint on the building was chipping and there were cracks in walls and ceilings. The building looked very much in need of repairs and perhaps even at the end of its lifespan. It was quiet in the hallways while classes were in session.

The school curriculum followed a traditional high school curriculum model with core classes including English language arts, math, science, civics and social studies and electives. However, at the time of my study the school had been making changes to the curriculum that introduced more in-depth senior projects, additional electives, and science laboratories in collaboration with a local university with a school of education. In my observations of school improvement team meetings, participants discussed their fear of losing students to a charter school in the city. They discussed how additional electives might stem this tide. The teachers and staff that I came in contact with at the school had great pride in their school and in their students, and believed in their potential. However, there were concerns about their ability to move forward productively, given deep divisions between leadership, teachers' and teachers' unions; these concerns would be uncovered in this study during interviews, and through direct observations in school 
improvement team meetings. An additional factor was the fact that, a few years prior to this study, the school had gone through a highly publicized takeover by the state, which included firing all of the teachers, though approximately half were hired back in the end. Despite these issues, the staff and leadership I interviewed and observed in meetings were committed to positive improvement in the school and, though frustrated, were hopeful.

I chose to study this school because I was aware that the superintendent, who had been hired during the state takeover, had demonstrated a commitment to student voice, parent engagement and community involvement, in particular the involvement of parents, youth, nonprofits, and local colleges with schools of education. Graduation rates had also improved significantly during this time. I felt it would be a strong place to view the impact of community engagement efforts through the lens of the efforts of a school improvement team at the school.

In interviews with leadership and school personnel, and through observations of school improvement team meetings, it became very clear that the wounds from the state takeover were still fresh, with continued conflict between leadership, teachers and the teachers' unions, that resulted in a challenging environment for the school improvement team. There were divisions between teachers who were inclined to side with the new leadership and others who remained faithful to the teachers' union. Some teachers expressed frustration at being stuck in between the two sides. It seemed all were trying to operate in good faith but all had trouble overcoming their differences. In interviews, leadership revealed that they felt that since the union contract only allowed for participation from one parent, one student, and one business leader or community member that a school improvement team was not going to be effective as a multiple 
stakeholder engagement entity. This restriction was confirmed through my review of the teachers' union contract with the district. The superintendent and the principal also both felt that the union president, who attended meetings despite not being an official member of the group, created a chilling effect in school improvement team meetings by continually asserting that agenda items should not be discussed because they were negotiated items between the teachers' union and school leadership. Although I was not able to meet with union representative, I observed this dynamic in meetings as well. The superintendent stated in meetings and in interviews with me that she felt she could best negotiate with the union if she understood the feelings of teachers, which she hoped to get from these meetings. However, both sides remained at an impasse during the full school year while I conducted my research.

The superintendent informed me in interviews that the school improvement team that I was observing had been restructured by her because she felt that the previous iteration, which had been led primarily by teachers and the teachers' union, was not effective. The new format included a district-wide team that would meet three times a year to talk about district-wide issues, and a secondary team that would meet monthly together to discuss issues at both the middle school and high school levels. The goal of this new format was to create a more seamless connection between the middle and high schools, and site-based teams that would meet as needed to discuss specific issues at each school - elementary, middle and high school. On average, twenty-three people attended the district-level team from elementary, middle, and high school. Members of this district-level team included the superintendent, principals from all elementary, middle and high school district schools; teachers from all district schools across the disciplines of 
English language arts, math and science; representatives from English-as-a-SecondLanguage instruction; literacy specialists; the high school librarian; the Title 1 administrator; family support staff; and assistant principals. The meetings of the team referred to as the secondary team at the school had on average ten members, including high school and middle school principals, teachers, and support staff. The superintendent attended the first of these two meetings as well. The high school site-based team was made up of the principal and seven other members, including the high school librarian, teachers and special education.

In interviews, teachers revealed that they felt this structure did not allow them time to really discuss issues at their own school level. Some expressed that the previous structure had been more effective for including teacher voice. The high school-based team meeting, one of the site-based meetings, was only to be held as needed, and it was confusing to this researcher as an outsider to understand when that would be the case. Most of the secondary team meetings were cancelled and the only two site-based meetings were held at the very end of the school year in this study. An email I received from the high school principal and reprinted here best illustrates one of the main reasons for these cancellations, reasons confirmed in other interviews with leadership and with team members.

We are debating how our meeting will run. I will send you a message as soon as I know. I am hoping we can hold a site-based meeting instead at the high school but the union is saying no. You may see a waste of time meeting that will last a few minutes if we go with the union recommendation. If we go with mine, we will have a productive meeting and action steps for moving forward (High School 


\section{Principal, School 2).}

The focus of my research was on the high school but unfortunately this team only met twice, and only at the end of the year in May and June. Responding to the unique structure, I also attended the meetings at the other levels, which the high school team members attended as well. However, I only interviewed those that were members of the high school team. The first school improvement team I attended was the district-level team. It was held in a large room in the high school. The room had very little decoration and meetings were held around a very large conference table.

The secondary meetings were held at the middle school in the library, a comfortable setting. The middle school principal facilitated the first meeting and the high school principal facilitated the second. An agenda, determined by the principal, was passed around and there were lively discussions that took place. I would learn in later interviews, that team members felt that most of the decisions regarding issues discussed were made in advance by leadership and things were just presented to them for perfunctory feedback. Teachers stated in interviews that they were looking for consensusdriven decision-making but did it did not appear to them that this was taking place. The superintendent and principal revealed in interviews that they sought consensus as well but felt that the teachers' union president and requirements for the structure of the team outlined in the teachers' union contract prevented this. At the first meeting, I did observe opportunities for any member in the meeting to comment on what was presented. However, I also noted several instances where the union president would say that this should not even be an item under discussion because it was a negotiated teacher's union contract item. This would re-occur several times during meetings I observed and would 
create a palpably tense environment.

The high school site-based meetings occurred twice at the end of the year and the focus was primarily on identifying what areas of school improvement should be the focus of resources provided by outside consultant, in support of accreditation goals. The setting was comfortable, in the school library, and like the other meetings, took place right at the end of the school day.

As had been my finding at School 1, there were no parents, youth, business or community members present at any of the meetings I attended.

\section{Detailed Findings}

Research Question 1: Who are the stakeholders that are engaged in school improvement teams, and why were they chosen or asked to participate?

This question proved difficult to answer definitively because the membership of teams differed significantly at each school, as did how members were chosen for participation. However, there were some significant findings related to this question that were shared across both schools and are worth noting.

Who was Included

I tracked who was present in team meetings during observations using the stakeholder tracking form I had developed as one of the observation tools (Appendix C). I was introduced to those present in the meeting at School 1 at the first meeting I observed. Everyone introduced themselves at the meetings I attended at School 2. Membership as outlined in the state legislation requiring school improvement teams that were not included on either team were: 
- Parents of children in the schools

- Students in the school

- Business and community citizens, representative of the ethnic, racial and economic community served by the school. Specific business and community entities that my stakeholder form was tracking that could be considered to be in this category included: for-profit businesses; nonprofit and public agencies focusing on social services, health, and mental health; educational researchers or representatives from colleges and universities with schools of education.

School 1 also did not include teachers, outside of the special education director (who also taught students) and also did not include the principals. School 2 included the principal and included teachers from a variety of disciplines as well as the high school librarian.

However, there were some team members that were shared at both schools including:

- Superintendent

- Director of Curriculum

- Special Educators

- Social Workers/Family Engagement Specialists

- $\quad$ Literacy Specialists

The inclusion of these individuals indicates that there is a commonality among those leaders who profess a belief in multiple stakeholder engagement in decisionmaking (which was the basis for choosing the schools for study) in looking for expertise in the social-emotional realm, as well as in the realm of curriculum. Leadership also seemed to be seeking to apply a focus on a diverse array of students as evidenced through the inclusion of special educators. The inclusion of literacy specialists at both schools 
reflected the importance of literacy in schools today. I observed that curriculum related to English Language Arts was an important topic for discussion in meetings at both schools.

Neither state and federal department of education representatives nor consultants, researchers and accreditors were physically present at school improvement team meetings; however, state and federal regulation and requirements, together with researcher and consultant feedback, were all part of conversations I observed in team meetings and also were elements mentioned in interviews with stakeholders. The following list includes these additional stakeholders identified through this study:

- Educational Researchers/Consultants

- State Department of Education

- Accreditors

- Federal Government - Title 1 Regulations, Perkins Regulations

- Universities with education programs

- Consultants with field expertise

State and federal requirements were brought up in both interviews and in observations of discussions in meetings across both schools. My observations and interviews clearly showed that the state and federal requirements had a direct and significant influence on the teams' conversations and decisions. Some team members in interviews indicated that the voice of the state department of education was greater at times than the actual team members' voices. At times, it was also observed during team meetings that the state regulations trumped team members' interests or decisions. the role of the school improvement team and the influence of state regulations. Quotes from interviews with team members in School 1 illustrate this: 
There were times when [the state department of education was pushing stuff down our throat and I would say 'we are required to do this and this' and they [other members of the school improvement team] would say 'go shove it' and I would say 'I can't do that.' The impact was I was very confused. I have to represent the [school] to the best possible way to [the state department of education] while upholding what we believe and what we hope to be true and what we hope to be true in the future, and they are often in conflict (Curriculum Director).

Similarly, the Special Education Administrator at School 1 also said, "I think it is identifying areas where we could go from good to great, not so good to better, problem solving, utilizing resources, new directions, in addition things that are presented [by the state department of education] that we have to manage.” The Director of Professional Development at School 1 indicated concern about what they were asked to do stating, "if you ask me what the school improvement team was I would say 'who cares', that it is some dumb thing that [the state department of education] wants and it is some political bullshit."

Additionally, when asked how closely the team follows its mission, one of the administrators from School 1 stated, "When other forces come in, mandates by [the state department of education], it sets up conflicts in how we think things should be done and should be rolled out. It gets challenging to maintain the vision and the mission in light of what has to be done." When asked about relationships with other team members the administrator stated, "[Another team member] gets caught up in [the state department of education], hates the mandates, really wants to just do her [School 1] thing and sometimes you have to drink the Kool-Aid. She spends a lot of time lamenting things she 
has no control over and I just wait for it to be done." When the social work administrator from School 1 was asked how they are engaged in the work of the school improvement team her reply was, "I am always mindful of systems and adherence to policies when we are having discussions about implementing changes."

In School 2, the state department of education also came up often as a driving force in team discussions, as did issues around accreditation. The following quotes from interviews highlight School 2's commonality with School 1 when interviewees were asked how they were engaged in the work of the school improvement team:

I have learned myself how things that are done by [the state department of education] affect us, how the legislature affects us, how positions administrators take affect us and how decisions unions make impact students. I have learned how [decisions about] student learning, which should be our top priority, are often made by a large group of contingencies, union, administrators, [state department of education], confounding learning and teaching, which is our job, I feel like it is pulling us in different directions (Science Teacher, School 2).

The Librarian at School 2 expressed the following with respect to the role of the school improvement team "....we need to meet more frequently because of our work with [accreditation] and our work with [a consultant] ... As we have narrowed our focus to responding to [accreditation] threads, this might define the role for what we are doing." And when asked to talk generally about the school improvement team from her perspective the special educator stated, "Decisions are made when decisions are made...It doesn't go through the [school improvement team]. It is just a formality because it is a law." And when asked generally "what haven't I asked that I should know about the 
school improvement team" the special educator stated, "[accreditation] - all the [accreditation] stuff." When asked how particular expertise is recognized by the group the special educator also stated, "I am not sure that I would say that any significant decisions have come to us except in the last few days when we were talking about [accreditation] and I think most of those decisions had already been made.” When asked how school improvement team work impacts the school the Superintendent of School 2 stated, "We have an overwhelming abundance of data - we meet quarterly with [the state department of education] through the school reform plan. So we are constantly making those reports and turning them into dashboards and it has been a good process." And when asked about engaging other stakeholders in decision making she stated, "It was intentional on our part and [the state department of education]...to institutionalize the partnership we now have with [university partner]." When asked where final responsibility for decision-making lies:

If anything we talk about is decided by the union, [union] leadership says - 'that belongs at negotiating table.' It closes discussion. It is unfortunately a three way discussion because [the state department of education] now sits at that table. Toward the end of the negotiation cycle [the state department of education] had decided they were a part of it and they didn't see anything wrong when [the union president] said elections, no parents, etc. and it was agreed to without management at the table and therefore it took this very different bent (Superintendent School 2).

When asked generally to tell me about the school improvement team from his perspective the high school principal in School 2 stated, "The goal for the [school improvement team] 
is coming to look at staffing concerns because of decreasing enrollment and pull out [accreditation] recommendations and see that is how we have to move and use [the] site based [school improvement team] to do that." When asked how the school improvement team impacts his decisions he said, "It hasn't impacted any decisions I have made as of yet. As we begin to look at [accreditation] recommendations, like the grading system, they will be much more purposefully involved."

These quotes from both schools clearly illustrate the direct influence that state department of education regulation and requirements by accrediting bodies have on school improvement team discussions and school decisions in general. Therefore, it was clear that both the state department of education and accrediting bodies represent stakeholders with a voice at the table, if not an actual presence at the table.

Overall, the findings from the first research question make it clear that answering the question of who is engaged in school improvement teams and why were they chosen to participate is not a simple one. The findings do indicate that those chosen were not necessarily in accordance with what was outlined in the state legislation and that there were many stakeholders listed in legislation who were not included. There were also stakeholders, such as the state department of education, that were not at the table but that had the power and influence of their requirements to create a large presence in team discussions. However, there were stakeholders in attendance at the team meetings that were shared across both schools including the participation of the superintendent and those with expertise across education and social-emotional realms including in curriculum, social work/family engagement, literacy, and special education. 
Why Were These Stakeholders Included and Not Others

After analyzing who was represented on the teams, it was important to try to understand why particular individuals were chosen to participate on the teams and why others were not, regardless of legislation that required it. The following findings are related to the second part of question one, which focused on why the stakeholders were included.

The first finding was that teams were not constituted in accordance with school improvement team legislation but instead by decision makers' beliefs about which participants would be best able to help them make decisions in that particular setting. Ultimately supporting the principals in their work, given the structure of the teams, became a focal point.

The finding that leadership chose participants, instead of following school improvement team legislation, is highlighted in the responses the superintendents' of both schools gave to the interview question "Can you tell me about the school improvement team from your perspective?"

I realized who I needed to be talking with all the time...I am always the person who feels like I shouldn't be making decisions by myself. This team supports the work of the principals and they all have people they supervise that work with principals and they all need to be on the same page. I meet directly with principals all the time, and they don't, and I felt like we needed to be on the same page (Superintendent, School 1).

At School 2, the Superintendent shared the following with respect to this: 
We had school improvement teams and every time I would go to one of their meetings it was just a complaint session. And the poor principal is sitting there being bombarded by teachers after school with complaint after complaint, no ability to say anything. No parents because we don't hold it after school, no business partners, and not following the law in terms of demographic participation. So over the course of the first three years we observed all of this and we made a firm commitment to attempt to do something different and to formalize a different approach and instead of having seven individual school improvement teams, because we are a small district, we thought what if we combined it all and had district school improvement team. This was how it was initially proposed - we would have elected members from every school building and we would match those individuals with parents, also elected, and membership from each of our partnerships. That was the original proposal. Somehow it was decided that had to be a negotiated item [with the union] (Superintendent, School 2).

The legislation plainly states that parents, youth, and community should be engaged. Analysis of the interviews provided clear feedback from participants on why that wasn't happening in schools, in particular when the superintendents professed a great desire for inclusion of parent and youth voice and had provided innovative outlets in other places in their schools for that voice. Analysis of the interview data contributes to the next finding that both leaders and members of teams at each school wanted to engage parents, student, and community voices but felt that the way the team was structured presented barriers to this engagement in the school improvement team setting. 
Additionally, they felt that other structures already existed outside the team for the appropriate engagement of these voices. The following quotes from numerous one-onone interviews with team participants at both schools identify barriers to parent and/or student participation on the school improvement teams.

The first set of quotes are from five of the six participants from the School 1 team. They primarily focused on the fact that the school engaged parents in other ways that were more natural to their interests and that the hope from team members was that these other engagements opportunities would filter up to the school improvement team. However, they acknowledged that there was not a formal structure for ensuring that this took place. In all my observations I was not able to find any evidence of the engagement with parents and youth outside the team clearly being brought back to the team. Here are the barriers to parent and youth engagement in their own words from team members at School 1:

Parents are not going to come just to talk to you. They will come if there is something with their kids... I have had my own student group, each principal has their own student government group - they meet every other week to ask questions or to ask them for feedback (Superintendent, School 1).

In the past [we] tried to meet the requirements of all the people that were supposed to be in it [the school improvement team] regularly and all that...We get tons of info from parents at campus level groups, exhibitions, parent-teacher meetings. We get almost zero participation at required whole school meetings. People feel very connected to their teacher, their small school, and less connected 
to the whole school...The hope is that the parent tells the teacher, the teacher tells principals, the principal brings it to team...I have had back and forth with [the state department of education] many times about this. We try to roll up information but we don't do a super successful job in a formal way but if the issue is big enough it comes up. I wonder if it comes up...Kids have personalized goals and what they need to meet their needs. It is less important to have a document that [the state department of education] might audit at some point... (Director of Curriculum, School 1).

The engagement happens on such a micro level, with the kid. Parents are so involved in their kids' education that I would say 'school improvement team whatever'. But I have seen since in administration, I am not sure that parents know that they can have more of an impact on the whole school. I feel they knew more when the school was smaller...[The state department of education] is only looking at engagement through one lens - we engage parents so deeply, directly through their kid. If a parent is coming in three or four times, the parent is always here, they are always on the phone, the principal is engaged...There is so much engagement happening outside of the school improvement team... (Director of Professional Development, School 1).

Students are represented because that is the core of all of the work - doing what is best for our kids. Maintaining individualized, personalized education. Maintaining that balance...I am trying to remember if there have been instances where 
students have come into those meetings. My feeling is yes, but I cannot come up with any instances in this moment. Students are represented because their needs are what drives those meetings... There is so much parent engagement and involvement here and parents are so present that there is representation in terms of those needs. I think as issues come up they get responded to. There is not a formal avenue for that, but parents definitely have an impact on what has happened (Literacy Specialist, School 1).

As a team, it is something we could do to help parents have an even stronger contribution. Of note in the model - parents, family members, guardians are invited to participate as much as possible. Exhibitions, student evaluation - they have a lot of voice because they are part of their students' evaluation and progress... [There are] parents everywhere who comment that their experience is that the [superintendent] is very responsive to them. She prioritizes that in a big way and parents are able to request a meeting with her directly without going through any other stuff. We have not yet invited parents to [the school improvement team] meeting. It is something to consider.... On the radar is continuing to grow the feedback that roles up from us, from parents and families (Social Worker, School 1).

School 2 also identified significant barriers to parent and youth engagement on the school improvement team and also framed their barriers in terms of the structure of the team not being conducive to engagement, though the specifics were different. As in 
School 1, they felt that many rich parent and student engagement opportunities were happening outside of the school improvement team.

The decision makers in School 2 were the superintendent, the high school principal, and the teacher's union representative. Although the teachers' union president was not available for interview in School 2, the negotiated teacher's union contract language, as outlined in the methodology chapter on participants, and that I included in my review of documents, stated that only one parent, one local business leader or community member, and one student, in specific the high school student council president, could participate. The contract also stated that six teachers were to be elected by their peers. However, even these regulations were not followed because parents and students were not present in School 2 team meetings. The superintendent expressed that this was because one parent alone or one student alone did not feel comfortable participating, in particular because in the previous year the caustic conversations between leadership and the unions made students and parents feel uncomfortable in this setting. Following are quotes from leadership and other school improvement team membership that highlight their beliefs about structural barriers to parent and youth engagement on the team. In the findings under research question \#7 the reader will see the other ways the school engaged these groups outside the team.

The parents stopped coming because we could only elect one after [union] negotiations were done because, god forbid, there was equal representation of parents and teachers and only one parent [could be] represented after negotiations and it just doesn't work that way. We are living with it but we are not happy with it because we feel we are missing the boat of real input. We don't really get to 
discuss things and have the joy of reaching consensus - just a false hope at this point in time. We have not suggested we abandon it because that would bring us to [the previous structure] which had not proved worthy either. We are hopeful that this will work because there should be a change in union leadership eventually and we hope we can wait it out (Superintendent, School 2).

The meetings used to be open to parents and we had one parent that came a few times but for the most part we don't have parents coming. We tried doing evening meetings a couple of times but it didn't make difference except that more [staff] couldn't come because they had family obligations. (Librarian, School 2).

The High School Principal at School 2 confirmed this by stating, “A parent hasn't been attending. We are supposed to have two parents and one student and we have none. Why would they? The student feels overwhelmed and not connected. Parents begin to feel uncomfortable, especially around that type of behavior." It must be noted that the Principal had described the behavior of many of the team members previously as:

A level of unprofessional attitude and behavior that isn't ok. Not just between superintendent and union but with colleagues. It is unreal. People had to leave the committee because of that....[You] should show up because you want to be there and then stipend the parents and create a scholarship for student or something that is meaningful to them (High School Principal, School 2).

The findings to the first research question are summed up in the following table:

Table 1. Summary of the types of stakeholders engaged and why they were chosen. \begin{tabular}{|l|l|}
\hline$\#$ of findings & discreet findings \\
\hline$\# 1$ & $\begin{array}{l}\text { Parents, students and community members, though required in the legislation to } \\
\text { be participants, were not on the team at either school. }\end{array}$
\end{tabular} 


\begin{tabular}{|l|l|}
\hline$\# 2$ & $\begin{array}{l}\text { Team members shared across both cases included the superintendent and school } \\
\text { staff specializing in both the education and social-emotional realms, including } \\
\text { curriculum, social work/family engagement, special education, and literacy. }\end{array}$ \\
\hline$\# 3$ & $\begin{array}{l}\text { Decision makers' constituted the teams based on who they felt would best be able } \\
\text { to support the principals in their work given the team limitations and structure. }\end{array}$ \\
\hline$\# 4$ & $\begin{array}{l}\text { The state department of education and accreditation requirements had a "voice" at } \\
\text { the table, though representatives were not present as members of the team. }\end{array}$ \\
\hline$\# 5$ & $\begin{array}{l}\text { In each schools both leadership and other team members perceived barriers to } \\
\text { including students, parents, businesses and community on the team due to the } \\
\text { structure of the team, yet each case presented unique structural barriers. }\end{array}$ \\
\hline
\end{tabular}

Research Question 2: In what ways, if any, are the stakeholders engaged in school improvement teams?

As with the first research question, there was no simple answer to this question. However, there were some shared findings across both schools that provided important insights into what authentic engagement and collaborative decision-making means to participants in the context of school improvement teams. The main finding from the study when looking at this particular research question was that, while engagement varied significantly at each school, when team members were asked about the impact they had on decision-making, they referenced the degree to which decisions were made through consensus. Other findings related to this research question were gleaned from observations of how the teams functioned at each of the schools. It was remarkable that the actual structure and facilitation of the meetings was very similar in both settings, despite the highly variant school cultures and school improvement team cultures.

\section{The Importance of Consensus}

The following quotes are from respondents in School 1 and School 2 to the interview question "How does the school improvement team impact decision-making in the school?" Various quotes from the research in School 1 illustrate the importance participants place on consensus when assessing how their efforts impact decision- 
making. The Director of Professional Development at School 1 stated, "I think it is a space where we can hash out the details and really look at how something will work and create something and bring it back and I think the leadership team trusts our work.” And the Literacy Administrator at School 1 said, "It is not something where administration says 'this is what we are going to do' and it is done. There is more of a voice." The Special Ed Administrator at School 1 said, "It is very collaborative but the final decision will be [the superintendent's], and that is accepted, but everyone feels respected." When asked about any constraints on the team's decision making, No, the only constraint is really a vote. There is not a procedural vote. If there is conflict about a decision, if she (the superintendent) says it won't be done it won't be done. Generally it seems to often be. There are cultures where the processing information happens from debate...moving an idea forward and playing it out for the most part...I think that while people disagree, more often a lot of ideas are bandied about to get to a solution" (Curriculum Director, School 1).

When leadership in School 1 was asked "How does the school improvement team impact your decision making" and "Are there any constraints on decision making school improvement team makes?" the response enabled triangulation with what was heard from other team members and observed in meetings. The following response confirmed that the Superintendent, as the decision-maker in School 1, does endeavor to provide a consensus-driven decision making environment, enabling the team members to feel engaged in the decision-making process. The Superintendent stated, "I guess on this team if folks are saying they need something, or those kinds of things, or if some of the principals are not doing something, I can hear from enough people that things are not 
happening then I will go and make things happen." When asked about constraints on the team's decision making, the Superintendent stated,

It is just money I would say, plus if they wanted to change something totally out of the blue they couldn't do it because the principals are the ones that are going to follow through and it has to be thought through and processed. If you really want it to happen you need to bring everyone together. If you have a great idea, it has to go through a process, otherwise you have a great idea that is not going to happen. (Superintendent, School 1).

Many observations of the team meetings at School 1 confirmed what team members and leaders were saying in the quotes above. I often heard lengthy discussions regarding a key school improvement issue that resulted in a final decision that represented team members reaching consensus. This would be followed up at the next meetings as decisions were made.

Quotes from School 2 school improvement team members also clearly illustrate the importance of whether team members felt they had a collaborative role and a consensus-based role in decision making. In interviews they were also asked the question "Does the school improvement team impact decision making in the school?" Participants were clear that they did not feel decisions were driven by consensus, but instead were made ahead of time and simply brought to them for discussion. It was also clear that they felt decisions should be made by consensus in order for them to feel that their involvement had an impact.

Maybe we are able to make some small decisions but the decisions we are making are not really impactful when it comes down to it. Part of it to me is we are given 
options but we don't have the power to make decisions... A lot of what we talk about are decisions someone else has made (Science Teacher, School 2).

The Special Educator in School 2 stated, "Decisions are made regardless. It doesn't go through the [school improvement team]. It is just a formality because it is a law." When asked about the team's relationship with decision-makers, the Librarian in School 2 stated, "I think the only real decision maker is [the principal]. I am not really sure how much input he had in things that I think are actually [the superintendent]...” Additional responses from interviews with leadership in School 2 corroborate the responses of other team members. The Superintendent in School 2, when asked about constraints on decision-making, stated, "Yeah - I think there shouldn't be, but the very structure of it stifles real discussion." When the principal was asked about the impact the team had on his decisions he stated, "It hasn't impacted any decisions I have made as of yet. As we begin to look at [accreditation] recommendations like the grading system they will be much more purposefully involved." When the Principal was asked whether there were constraints on the team's decision-making he said, "No, I think it all comes down to how willing they are to engage in conversation that is forward thinking and productive. They become their own obstacles."

My many observations of team meetings confirmed information shared in interviews. It seemed that the topics brought to the teams were already fairly far along in their development. Although team members were able to raise questions and concerns, this did not lead an extensive conversation that resulted in consensus. The expressed beliefs of participants in interviews suggest that stakeholders only felt engaged if the 
process was consensus-driven. They were not content with just giving input and suggestions.

\section{Additional Findings Related to How Team Members Are Engaged}

During my observations of team meetings at both schools I was able to identify additional elements of how participants were engaged in school improvement teams. Despite two very different school models and school improvement team cultures, many of the elements of the meetings were relatively the same.

At both School 1 and School 2 there was always an agenda for meetings. School 1's agenda was typically shared in advance in a Google doc, and School 2's agenda was passed out at the beginning of the meeting. All agendas were easy to follow. Because of this, everyone seemed to be clear on the issues that were to be discussed. In each meeting there much discussion on the topics raised. However, as I noted above, in School 1, the goal seemed to be deciding how to best frame the issue before discussion in order to reach consensus, whereas in School 2, the issues were clearly framed ahead of time and the goal seemed to be to provide opportunities for questions and general thoughts with the balance of the time tipped more toward presentations to the group.

The following summarizes shared findings from my observations at both schools regarding how stakeholders are engaged.

- All meetings followed an agenda that allowed for discussion among team members, with somewhat more time for this at School 1 and less at School 2.

- There were many opportunities for team members to gain clarification on an issue, with somewhat more time for this at School 1 and less at School 2. 
- There were very few times at both schools when ideas or issues under discussion were brought to a larger stakeholder group outside of the meeting for deeper discussion. When it did happen the larger group was typically teachers. Even on the rare occasions when this did happen, the results almost never carried over clearly to the next meeting. There was one exception in School 2, when discussing changing the timing of vacation days. All of the teachers in the school received a survey regarding their preference and that carried the day. However, even then, some teachers that were on the school improvement team raised the question of how thoroughly the issue had been discussed with teachers and whether the survey had language that biased in favor of a particular response.

The following table illustrates the key findings for the second research question:

Table 2. Summary of the ways in which team members were engaged

\begin{tabular}{|l|l|}
\hline$\#$ of findings & discreet findings \\
\hline$\# 1$ & $\begin{array}{l}\text { Team member engagement styles varied significantly in each of the schools, } \\
\text { however when asked about the impact the team had on decision-making, } \\
\text { participants on both teams referenced the degree to which decisions were made } \\
\text { through consensus as the benchmark for engagement. }\end{array}$ \\
\hline$\# 2$ & $\begin{array}{l}\text { Agendas and facilitators provided for some give-and-take among team members } \\
\text { on issues discussed (though present at varying degrees at each school). }\end{array}$ \\
\hline$\# 3$ & $\begin{array}{l}\text { There were opportunities for members to gain clarification on issues in meetings } \\
\text { though present at varying degrees at each school). }\end{array}$ \\
\hline$\# 4$ & $\begin{array}{l}\text { There were rare opportunities in both schools to bring ideas to a different or larger } \\
\text { stakeholder group but these opportunities lacked focus or a clear process of } \\
\text { communicating feedback to the team. Typically, this engagement was focused on } \\
\text { teachers, and occasionally, parents. }\end{array}$ \\
\hline
\end{tabular}

The next research question studied went beyond who is engaged, how, and why to focus on the content of the engagement.

Research Question 3: What types of decisions do the stakeholders engage in? What types of decisions are they not engaged in? 
As with all questions, I focused primarily on the findings that were shared across both schools. As already noted, the schools varied in terms of whether the stakeholders were actually engaged in making the final decisions on the issues brought before them. I was unable to find anyone who could speak to the original intent of the law when it was initially enacted, however, my observations revealed a high level of commonality in the types of issues that the school improvement teams discussed. The agendas provided at each meeting, together with interview questions, confirmed the commonalities I observed.

The topics discussed at both schools during school improvement team meetings could be considered core issues in the function of a school, as they included curriculum, student assessment data, professional development, and state department of education and accreditation requirements. Also covered during meetings at both schools, though to a somewhat lesser degree, were approaches to personalized/differentiated learning, approaches to student behavior issues, and work with outside partners and consultants.

Curriculum was heavily represented as a topic of conversation at both schools in their school improvement team meetings. School 1 focused nearly the whole year on how to improve the literacy levels of students. For instance, discussions focused on different instructional methods for reaching students at different literacy levels, including students with special education needs. Additionally, the School 1 team spent much time discussing professional development in this area and how to help teachers set and track literacy goals for individual students. At School 2, during the two site-based meetings at the high school level, held at the end of the year, the team discussed curriculum as a general area for school improvement focus. The goal was to look at the curriculum based on 
accreditor recommendations in partnership with consultants who were able to provide research support, funded through grants. Student portfolios and their function and scope were also discussed in the district level meetings. Curriculum was also discussed at district and secondary team meetings in terms of creating uniform curricula in English Language Arts, Math and Science at each grade level and coordinating across grade levels and from middle school to high school. Curriculum was a clear focus area at both schools studied.

Student assessment data was also discussed at both team meetings, in particular how to use assessment data to make better decisions to meet student needs. During observations at School 1 and School 2, it was clear that the schools struggled with how to use state and district assessments that could support the identification of student needs in order to identify appropriate interventions.

Professional development was also a key topic at both schools. In my observations at School 1, I found that professional development was discussed in the context of nearly every school improvement focus area. In School 2, however, I found that professional development was discussed primarily in terms of the appropriate schedule for summer, the balance of hiring outside consultants versus utilizing teachers to share instructional practices during professional development blocks, and general areas for professional development, related to curriculum changes. In both schools, professional development conversations included what teachers needed, best delivery approaches, and getting/seeking feedback from teachers about ideal professional development opportunities. 
State department of education requirements were discussed at both schools, in particular the new state student assessment. I observed many meetings in School 1 where new state department of education requirements for student vocational certifications were discussed. State requirements were also brought up numerous times in stakeholder interviews in School 1 and School 2, as noted in previous sections. School 2 also focused on accreditation requirements. In the two high school, site-based meetings at School 2, I heard discussion on how accreditation requirements and how outside grant-funded consultants could support achievement of accreditation requirements. Also discussed was how school improvement efforts could be aligned to what the accreditors had suggested.

The following topics were also discussed at both schools at more than one team meeting, but to a somewhat lesser degree:

○ personalized/differentiated learning: at both schools I observed personalized and differentiated learning as core focus areas for school improvement at more than one team meeting;

○ approaches to addressing student behavior issues: at both schools I heard discussions at more than one meeting on whether new behavior interventions being tried were having the desired impact;

○ work with outside partners/consultants: teams at both schools discussed, at more than one meeting, the role of outside partners or consultants in the context of support intended to help the schools with their school improvement goals. In the case of School 1 this focused primarily on a consultant firm that would help with accreditation requirements and a 
partnership with a local university. In the case of School 2 this focused on field experts in literacy and behavior interventions.

The following table provides an overview of the key findings related to the third research question:

Table 3. Summary of cross-case decisions the team members were engaged in.

\begin{tabular}{|l|l|}
\hline$\#$ of findings & discreet findings \\
\hline$\# 1$ & $\begin{array}{l}\text { The main topics discussed included curriculum, professional development, student } \\
\text { assessment data, and state department of education and accreditation } \\
\text { requirements. }\end{array}$ \\
\hline$\# 2$ & $\begin{array}{l}\text { Additional topics discussed less often, yet covered in both schools' school } \\
\text { improvement team meetings included personalization/differentiation, approaches } \\
\text { to addressing student behaviors; and work with outside partners and consultants } \\
\text { supporting school improvement goals }\end{array}$ \\
\hline
\end{tabular}

Research Question 4: In what ways, if any, do facilitators support the process of multiple stakeholder engagement in school improvement teams?

The findings around the role of the facilitator were similar at both schools, again despite very different school cultures and school improvement team cultures.

\section{Inside Facilitator}

On both teams the facilitator was also a key decision-maker in the school and not an outsider with a specific specialization in facilitation. At School 1, the facilitator was the curriculum director and at School 2 there were two facilitators, the principal at the site-based meeting and the superintendent at the district level meeting. At the secondary meeting the middle and high school principals took turns facilitating. I observed the role of facilitator at both schools to be primarily keeping the agenda on track and enabling feedback from the group. In interviews, the curriculum director at School 2 indicated he had essentially fallen into the role of facilitator because no one else was taking it on and the superintendent preferred distributed leadership. At School 2 it was unclear how it had 
been decided that the role would fall to the superintendent for district-wide meetings and to the principals at site-based meetings. It seemed to reflect a top-down approach to facilitation and decision-making.

\section{How the Facilitators Ran Meetings}

An agenda was typically handed out at the meeting or sent out in advance and the topics were typically mentioned briefly at the beginning of the meetings. During interviews, team members at both schools confirmed that the facilitator was the one that primarily created the agenda but that other key decisions-makers had input into this as well. During observations, I identified that notes were taken by a member of the group. In School 1, the notes were taken by the facilitator, and in School 2, notetaking varied but someone usually volunteered to take notes at the beginning of the meeting.

On both teams, the facilitator helped to ensure that, to some degree, next steps were followed up by delegating actions to be taken either to an individual or a subcommittee. As an observer, it appeared that these roles were taken on voluntarily and through consensus.

Facilitators for School 1 and School 2 school improvement team meetings provided opportunities for people to bring up new ideas in the meeting, which were not on the agenda. At both schools they asked for this feedback at the end of the meeting. However, at both schools, the agenda was primarily set in advance, in terms of topic areas, and was usually quite full at both school teams, so there was limited time to raise new ideas or concerns.

The following table represents the key findings related to research question four: Table 4. Summary of the ways facilitators supported the process of engagement 


\begin{tabular}{|l|l|}
\hline$\#$ of findings & discreet findings \\
\hline$\# 1$ & $\begin{array}{l}\text { The facilitator in both schools was an existing leader in the school, not an outside } \\
\text { facilitator. }\end{array}$ \\
\hline$\# 2$ & $\begin{array}{l}\text { An agenda was created by the facilitator prior to the meeting. School leaders often } \\
\text { contributed to the agenda as well. }\end{array}$ \\
\hline$\# 3$ & $\begin{array}{l}\text { On both teams the facilitator helped to ensure next steps were followed up to some } \\
\text { degree by delegating to an individual or subcommittee or preparing the next } \\
\text { agenda to incorporate follow up. These roles were typically taken on voluntarily. }\end{array}$ \\
\hline
\end{tabular}

Research Question 5: What are the strengths and difficulties shared by schools attempting multiple-stakeholder engagement through school improvement teams?

There were strengths and challenges apparent in the research because these were often observed or frequently cited in interviews at each school.

Technology as a Strength and Challenge

Though it did not come up in the interviews, it was very clear from observations and documentation of team meetings that both schools were in a time of transition as they moved toward providing and sharing more information electronically. In the schools studied, information was being moved to an electronic platform primarily for the reasons of providing access to shared documents for review by team members before meetings, to provide access to student assessment data for team members to use in decision-making, or to get feedback from a wider group of stakeholders. It must be noted that this last item was discussed at both schools but not fully brought to fruition during the 2014-2015 school year. Coding and analysis of observations revealed that both school teams often discussed using technology to:

- seek feedback on agenda items,

- follow up on ideas presented at in person meetings,

- enable more stakeholders outside the team to provide electronic feedback, 
- and enable more people to participate that might otherwise be restricted, or not explicitly invited, due to scheduling or space.

It was clear from observations of meetings that both schools recognized the power of technology to enable better collaborative discussions, yet struggled to some degree with technological limitations. Coding of observations at both schools noted multiple instances where participants had trouble accessing technology to collaborate. Both schools had challenges with technology not working as intended, which slowed down the process of decision-making. Team discussions also identified as an issue the varying levels of teacher or staff expertise in using technology.

The Budget Process as a Challenge to Consensus-Driven Decision-Making The budget was mentioned only a couple of times in team meetings and interviews at both schools. However, when it was mentioned, it was discussed by school leaders, who understood the connections between the budget and decision making. They discussed it in the context of what the school improvement team wanted to do and what it could actually accomplish. I observed at team meetings that the budget was not up for discussion in general in the school improvement team meetings. Yet, in interviews, leadership at both schools identified the budget as a constraint to consensus-driven decision-making on the school improvement teams. Budgeting was also discussed as a constraint in meetings observations. The following are quotes from superintendents in both School 1 and School 2 that reflect conflicts between the budget process and the school improvement team process, though for different reasons.

If I hear from enough people that things are not happening then I will go and make things happen. But budgets are set. You can't start changing them in the 
middle of the year. People can say they want all kinds of craziness but it can't happen. We may change the following year. If the state says we need more certifications, how will that happen? Something will have to go. That is the conversation. People don't understand. You cannot just add things. If you want something then something else has to go. I am the one who has to say that (Superintendent, School 1).

Why haven't we talked about distributing the budget in such a way so the schools get a particular amount and [decide] how they are going to spend it. Instead [the union negotiates] 'you will have one music teacher, one librarian, and twenty phys ed teachers.' Why can't a school decide? Maybe I want six librarians. That was the dream, the expectation that we had when we put forth the [school improvement team]. That we would role up our sleeves, look at our budget and see how can we better spend it (Superintendent, School 2).

\section{Challenges with Using Student Assessment Data for School Improvement} It came up often in team discussions that it was not clear to team members or teachers how to use assessments most effectively to generate school improvement goals that would benefit student achievement. Coding and analysis of observations noted many instances of discussions of this type at both schools.

I observed in various meeting discussions in School 1, that I was unable to capture well in written form, that highlighted the challenges with using data to understand and improve student academic progress. I also observed this same challenge in School 2 
meetings. Following is a dialogue from School 2 that illustrates the confusion around how to use assessments to make decisions:

It is time for us to start using data as part of what we do. I think it will be challenging to use [the state required assessment]. All of our students will look like they are struggling, which many of them are. I almost think if it is a priority I would like to see it taken on in common planning. The way we did it before. People looking at one set of data as opposed to 'here is what we need to do in biology teaching.' I think we are pretty aware that our kids are poor and have deficiencies. I am not sure if it leads to an action plan. (Teacher 1)

Can you include what we find in Google classrooms, like assignments routinely missed? (Teacher 2)

Have you seen [specific data system]. We all have access. (Teacher 1)

I didn't know it was called [name of specific data system]. (Teacher 2)

All of your students are listed in there and the data, what they scored. Anything they had. This would make more sense than if I had a conversation here. It is better to look at student or class data. (Teacher 1)

I think to your question of 'what was the outcome' I think it was just to highlight we have a big range of kids and we need to differentiate and meet their needs. I 
think that was what the outcome was. Are you questioning the validity of [state required test] versus [research validated quarterly school test] and what data to use? (Teacher 3)

I don't think we should use [the state required test] (Teacher 1)

There are ways of breaking down [research validated quarterly school test] to show that what skills students need to work on. (Principal)

They use a database of generalized responses. (Teacher 2)

I'd just want to know how to use it to drive instruction. (Teacher 3)

We should put data as a priority, and then talk about what is the point of looking at it, what to look at it. (Teacher 1)

That could be our $5^{\text {th }}$ priority. I agree assessment is very big. (Principal)

The findings from this research question illustrate strengths and challenges the schools had in using student assessments and technology to support decision-making. Also highlighted as a challenge, is the key role of the budget process in moving from decisions to implementation, and the challenges schools face in moving from student assessment to using the data from assessments to design appropriate interventions 
focused on school improvement. Following is a table that outlines the key findings from the fifth research question.

Table 5. Summary of cross-case strengths and difficulties shared by the schools studied in attempting multiple stakeholder engagement through school improvement teams.

\begin{tabular}{|l|l|}
\hline$\#$ of findings & discreet findings \\
\hline$\# 1$ & $\begin{array}{l}\text { Technology was both a strength and a challenge for improved information-sharing } \\
\text { and collaboration. }\end{array}$ \\
\hline$\# 2$ & $\begin{array}{l}\text { Leaders identified the budget as a challenge to consensus-driven decision-making } \\
\text { as it was decided by a different group, at a different time, separate from the school } \\
\text { improvement team. }\end{array}$ \\
\hline$\# 3$ & $\begin{array}{l}\text { It was not always clear to team members at both schools how to use student } \\
\text { assessments to support school improvement. }\end{array}$ \\
\hline
\end{tabular}

Research Question 6: Are there other multiple stakeholder engagement efforts connected to school improvement teams?

The findings from this question offered another opportunity to answer the question of why all the stakeholders listed in school improvement team legislation were not included in the school improvement teams.

At both schools there were opportunities for stakeholder engagement outside of the school improvement team, for engagement of parents, youth, businesses, nonprofits, researchers, businesses (in the case of School 1); universities with schools of education (in the case of School 2); and consultants and experts in the field. Interviews revealed that leaders, and some team members, felt that these opportunities provided a richer and more natural connection experience for other stakeholders and that these engagements often informally connected back to the school improvement teams. Leaders and team members often noted in interviews the informal ways in which they brought ideas from these groups back to the school improvement team discussions. However, neither the 
interviews nor the observations indicated any clear path back to the decision-making table; my observations confirm that none of these stakeholders were actually present at the decision-making table.

Although I did not observe these engagement efforts directly, quotes from School 1 and School 2 team members reveal the nature of these outside engagement efforts and how team members thought ideas might find their way back to the school improvement team and decision-making. The quotes are offered at length in this section because I believe they provide a rich description of other engagement efforts happening outside of the school improvement team. I did not observe these engagement opportunities directly as part of my research so the interviews provide the strongest evidence. They also appear to demonstrate how leaders and other team members see this connection back to the work of the team. The first set of quotes is from team members at School 1.

...we have a [business] advisory committee. It is my job to bring them together. I bring whatever information from that committee to this [the school improvement] team. That is how it works here. We don't have a representative from each perspective or role because we do utilize so many of them and it feels kind of forced (Director of Curriculum, School 1).

The [school improvement team] and strategic plan have a ton of crossover. (Researcher note: The Strategic planning process took place before my time observing the schools. It was noted by some team members that this process included multiple stakeholder perspectives in determining the broad focus of school improvement efforts that the school improvement team would then focus on). We do have open meetings sometimes... When we collect data from parents 
and mentors at exhibitions [other team member] represents real world learning and postsecondary access counselors. He will take things back to meetings. Anything with parents and mentors usually comes from the principals meeting (Director of Professional Development, School 1).

We bring what we talk about here to principals' meetings. Sometimes we will have principals come to a meeting because we can't duplicate the rich meeting [discussion]. Sometimes we will take what we do here and do the same things at principals' meetings... Sometimes we take what do here and have the same conversations at staff meeting...We will say 'how did it go?' and make changes from there. Sometimes we will do it at staff development - everyone is there so it is just easier...We may do different things [with parents] - every school has parent meetings, it could be individually with parents, students and teachers or a family night meeting. Or mailings to ask parents to come in. We have some staff who are parents so we might bring them in to have more conversations about what they think. We have lots of parents here all the time so we feel like the learning plan, meetings with kids, if we want to get anything communicated we do it there...We will say these are questions we need to ask parents - just a couple one time we had a parent pamphlet. These are two questions we want your feedback on. It goes from the advisor to the principal, from the principal to us. Or we hold a family night. We have college nights, all kinds of events. Parents are not going to come just to talk to you. They will come if there is something with their kids. We latch onto that, ask parents to give some feedback."...Same thing with students. I have had my own student group, each principal has their own 
student government group. They meet every other week to ask questions or to ask them for feedback. If we have an issue there they would meet with their student group.”...We do a million things [with nonprofits or public agencies]. There is... [the business advisory] board. They meet however many times per year. Our board gives input all year long (Superintendent School 1).

There are parents everywhere who comment and their experience is that the [superintendent] is very responsive to them. She prioritizes that in a big way and parents are able to request a meeting with her directly without going through any other staff. We have not yet invited parents to [school improvement team meetings]...We work collaboratively with outside agencies, [the public child welfare agency]...We endeavor to be partners, if they are working with our children they are working with us, whatever it takes to help the student and if that means they come here that is fine with us...I think our entire real world learning through internship model is based on collaboration with community businesses. It is at the core of our service delivery services. They come in and share with staff around professional development. Staff is out there meeting regularly, very visible in business community...Through work with the child and advisor it also drives feedback. We have had mentors give fantastic feedback. They can funnel feedback from advisor to principal to the [school improvement team] and some will write directly to [the superintendent] to share feedback and comments... When visitors come here they debrief and it would funnel. As part of 
our process we have information exchange - that is how that exchange enters [the school improvement team] (Director of Social Work, School 1).

From the quotes above and through other interview evidence it became clear that members of the school improvement team at School 1 feel they have strong input from the business community through a business advisory board made up of business leaders that mentor students in the school, as well as ongoing feedback on areas for improvement from business mentors. The school also engages parents in review of their student's work and has frequent parent meetings related to personalizing the curriculum for the child. Interviewees felt that parents were deeply engaged as a result of the school model. They believed parents have deep relationships with their student's teacher and the principal. These relationships were thought to open up lines of communication so parents were able to provide feedback regularly that makes its way to leadership. In addition, the social work and leadership staff identified as a strength maintaining relationships with a wide range of community nonprofit and public health and human service agencies. Leadership and team members in School 1 noted that their model personalizes education for each youth, and that through that process each youth participates in the design of their own personalized curriculum. Many of the team members felt that these engagement efforts make their way back to decision-making by the team organically. As an observer, however, I almost never heard decisions or discussions at the school improvement team meetings explicitly informed by someone bringing in those outside perspectives. Also, there was never an articulated expectation that these perspectives would be included in decision-making. 
The following are quotes from School 2 that discuss in their own words how multiple stakeholders were engaged outside the school improvement team and how ideas from those groups found their way back to the school improvement team.

We have a student leadership group of about fifty-three students that are involved in a number of opportunities. We took one to San Diego to talk about development of student voice and he has been a big part of transformation here. Our parent engagement program is part of the foundation that has allowed us to change the school community. At one point we had over 100 (community) partners and we had to prioritize. We still have lots of partnerships for class programs, field programs, academics. Our [university partner] partnership is the biggest. [a high level representative from the university] is now on our board of trustees. Our parent leadership group. We had a parent come with us too to present (Principal, School 2).

Well I think that the [superintendent's] forum. That is why having her at the table gives us so much more insight into what is going on, because she has that public forum. (Science Teacher, School 2).

Well, as of the last two meetings the [school improvement team] is now working with [a research consultant]...My understanding is [the consultant] can support schools in doing school reform...They can provide a person to provide support on changes. They can also do some research when we have particular topics that we want to know more about. They can do research and report back on findings so 
we can have more understanding of potential impact of decision (Librarian, School 2).

We have partnerships galore - [nonprofit], department of health, [university partner], just phenomenal work going on with... No input into decision making. Maybe [the university partner] will now that [a university official] has been appointed to Board of Trustees for the school...We have parent forums every month...We have student forums that students run themselves. They invite me when they want change in a particular direction. They are very vocal which is great...There is a 40-hour leadership program for parents that when they finish they get a badge that welcomes them as volunteers in our schools. There is a background check, they learn advocacy, they learn to advocate politely with right words and not get angry when things don't go their way. When I see them coming to a school board meeting as a group I am confident that it will be an appropriate and lively discussion...(Superintendent School 2).

It was clear through my interviews, illustrated by these quotes, that School 2 had rich engagement and leadership opportunities for youth and parents. They also had strong partnerships with nonprofits and a university with a school of education. As was the case with School 1, in team meetings at School 2, I did not observe any evidence of these efforts being connected back to the school improvement team in a clear way, or evidence of an expectation that the thinking of these groups would be incorporated into decisionmaking. And certainly these stakeholders were not represented on the team, as required in the legislation. 
In the first question I outlined how team members connected this to the fact that the structure of the school improvement team was not a natural setting from which to engage parents, youth and other stakeholders for a variety of reasons. It was only through the interviews that there were inklings that those on the team assume that in their own way they incorporated the feedback from those groups they engage with into discussions and decision-making with the team. It must be noted that this could not be verified in any way through observations.

Following is a table outlining the key findings from the sixth research question.

Table 6. Summary of the cross-case findings of other multiple stakeholder engagement efforts connected to school improvement teams.

\begin{tabular}{|l|l|}
\hline$\#$ of findings & discreet findings \\
\hline$\# 1$ & $\begin{array}{l}\text { At both schools there were other rich opportunities for stakeholder engagement } \\
\text { that leaders felt were more appropriate settings than the school improvement } \\
\text { team for engaging parents of children at the school, youth in the school, businesses, } \\
\text { universities with schools of education, health and human service nonprofits and } \\
\text { public agencies, researchers and consultants with expertise in the field of } \\
\text { education. However, the forms these engagement efforts took were highly variable } \\
\text { and there was not a formal mechanism observed for communication back to the } \\
\text { school improvement team, yet leaders and team members often felt they were } \\
\text { bringing these perspectives to the team to some degree. }\end{array}$ \\
\hline
\end{tabular}

Research Question 7: Is there evidence of authentic engagement (Friere, 1993), adaptive leadership (Heifetz, et al., 2009), and/or collaborative governance (Ansell \& Gash, 2007; Kania \& Kramer, 2011)?

There were numerous considerations when reviewing whether authentic engagement, adaptive leadership and collaborative governance were in place.

For the purposes of this study, authentic engagement was defined by borrowing from the critical pedagogy of Freire (1993) and Giroux (2011). The assumption was that if engagement is authentic, the participants will be educated about the larger systems at 
work, be aware of their individual needs, and know how these things connect.

Participants will then be empowered to participate and have agency in the change process.

The term adaptive leadership was defined by borrowing from Heifetz, et al. (2009) and refers to leaders that seek to gain input from a broad range of sources and have the skill set to engage a broad range of stakeholders.

Collaborative governance is defined by a set of principles set forward by Ansell and Gash (2007). They first define collaborative governance as "a governing arrangement where one or more public agencies directly engage non-state stakeholders in a collective decision-making process that is formal, consensus oriented, and deliberative and that aims to implement public policy or manage public programs or assets" (p. 544). The eight key elements that they identify for effective collaborative governance are the following: 1. stakeholders participating in all elements of the decision making process; 2 . addressing power and resource imbalances; 3 . taking a formal approach; 4. ensuring clear ground rules and transparency; 5. ensuring the presence of facilitative leadership; 6. ensuring broad participation is not simply tolerated but actively sought; 7. ensuring the process is consensus-oriented (even if cannot always be achieved in practice); and 8. putting the focus on public policies and key issues.

The proposition tracking form (Appendix C) supported analysis of this question, and analysis of the degree to which authentic engagement, collaborative governance and adaptive leadership were in place. In both schools there was a superintendent who believed strongly in leadership through consensus and had skills in engaging multiple stakeholder groups. Both of these schools also had broad and rich engagement efforts 
taking place. The barrier identified in the research was in wedding those perspectives into a true collaborative governance model through the vehicle of the school improvement team.

When looking solely at the functioning of the school improvement team, it did appear that School 1 had an adaptive leader who created an environment of collaborative governance with authentic engagement of those present. However, those present were a highly homogenous group, which only included administrators and did not include teachers, let alone students, parents, youth or community members. There was also only one leader present in the meeting, the superintendent. In School 2 collaborative governance was not achieved on the school improvement team, nor was there authentic engagement of all the stakeholders on the team. However, in this environment in School 2, leadership was shared and had to be negotiated between the superintendent, principals, and the teachers' unions. And there were teachers in the meeting in addition to administrators. This was a much more complex environment for collaborative governance and authentic engagement.

While both school teams differed in whether the stakeholders on the teams were authentically engaged in collaborative governance, participants shared ideas about what authentic engagement meant to them in the interviews. As noted earlier, both groups talked about whether or not leadership allowed decision-making that was consensusdriven or whether the leaders essentially made decisions on their own. These were the deciding factors in participants' assessment of how they felt about their own engagement. This assessment is also in line with the theoretical frameworks that guided this study, 
including authentic engagement (Friere, 1993), adaptive leadership (Heifetz, et al., 2009), and/or collaborative governance (Ansell \& Gash 2007; Kania \& Kramer, 2011).

Considering multiple stakeholder engagement through the lens of the theoretical framework established, and the school improvement team legislation, there does not appear to be direct representation on the team from many key groups including students, parents and community partners/community members reflective of the socioeconomic make-up of the cities and towns within these two school districts. However, there were nascent opportunities for authentic engagement through natural networks, which are discussed in more detail later. Team members also believed in the strength of their own expertise and believed they fully understood the issues under discussion and had the expertise, if not the ability, to contribute. This is also a key component of authentic engagement. The participant must have the capacity to engage. At least among teachers and staff in the schools, this is an existing strength when looking through this lens.

The final focus in this category was how outside regulations via the state department of education can affect collaborative governance and authentic engagement.

Natural Networks

The first finding focused on this research question was that there is no cross-case finding of authentic engagement of multiple stakeholders, and consensus-driven decisionmaking, inclusive of a wide range of participants (i.e. teachers, administrators, staff, students, parents, businesses, nonprofits and educational researchers, the school faculty and staff) on the actual school improvement team. Those stakeholders that did participate were not offered any specific training or support in their role, however, all were able to identify a connection to natural networks in their functional area of expertise. And nearly 
all sought to informally represent those perspectives as well as their own without prompting from group leaders. This is a potential strength that could be built on to move toward more authentic engagement and collaborative governance. However, these "natural networks" were not necessarily naturally occurring. Sometimes they were structures that simply brought together stakeholders sharing commonalities such as teachers engaging together in common planning time or parents coming together in a leadership training group. The important factor was that these networks attracted many from the group to participate and that the participants felt these were natural environments for them to share ideas and come to decisions.

Most team members interviewed identified that they were connected to natural networks and saw themselves as representing those networks to some degree when engaging with the team. While there was not a formal representation, this is perhaps a step in the direction of representation of a larger stakeholder group. The individuals on the school improvement teams had those networks and clearly indicated an inclination to at least attempt to represent those groups through discussion of issues with the groups, identifying group needs, or simply trying to put themselves in the shoes of that group. This natural disposition, evidenced in the quotes, toward engaging with natural networks and attempting to represent their interest as well as other interests, without prompting from group leadership, is an important finding relative to authentic engagement, adaptive leadership, and collaborative governance.

When school improvement team members at School 1 were asked if they represented anyone beyond themselves on the team, their responses were similar. The Curriculum Director stated, "It is my job to bring [the business] committee together. 
Bring whatever info from that team to this team." The Literacy Administrator said, "Sometimes it is just in casual conversation, but largely it comes up at common planning time - someone will say something and every one is like 'oh I know', so I am like 'oh we have an issue'." The Director of Social Work replied, "I represent my team. When timeline allows, I get their feedback and it drives my feedback." The Special Education Administrator replied, "We get tons of feedback from the [business] mentors. I think that information feeds how we plan for instruction. I would say definitely there is a lot of input that comes from outside people that we rely on.” The Director of Professional Development stated, "I mean I represent myself more than I like to admit. The stakeholder group might be imaginary - teachers and staff members who are also committed to the philosophy. When it is about a plan [I am] representing teachers." And the Superintendent said, “...Nonprofits or public agencies, we do a million things. There is ... [a business] advisory board. They meet however many times per year, our board gives input all year long.”

When team members of School 2 were asked if they represented anyone beyond themselves on the team they had similar responses to those in School 1. The Librarian stated, "We represent the school in general, how we think our colleagues would want us to be working with different things. I have the most contact with English, Social and Science, I don't have much with Maths." The Science Teacher said, "I would like to think I represent a group but unfortunately I feel I just represent the Science Department because I know where they stand. I have no way of knowing where anybody else stands..." The Superintendent responded to this question stating, "My entire experience and leadership style is geared toward shared decision making...We have partnerships 
galore... We just don't have them represented in any way in a management role in any kind." The Principal stated, "If I am pushing it is because of feedback I have received from parents, students or teachers. Very rarely do I feel I have something to implement that came from the top down."

\section{Stakeholder Expertise}

Each participant's time in the profession of teaching, individual and unique expertise, and confidence in that expertise, represented important parts of the participant's identity in terms of the contributions each felt they could make to the team. Respondents from both schools noted often that they felt they brought unique expertise to the team and they had confidence in that expertise. These contributions typically focused on their functional expertise, though some also noted their connection to the community and/or to students, or their history with the school or community or relationships with faculty and staff as areas of expertise that were potentially valuable to the team. While this does not translate directly to authentic engagement, it could potentially be a step in that direction, as there was a strong feeling of expertise and confidence that could be built upon. Since this feeling of expertise and confidence was found among staff in these two very different environments, it can at least be assumed when including a wide range of internal stakeholders (faculty and staff) that others might have this level of confidence and that could be a great asset to authentic engagement and collaborative governance.

When asked "Do you feel you have specific expertise or knowledge that you bring to the school improvement team?" The following were the responses among the team members in School 1. 
Yes, absolutely...my Orton-Gillingham training...Eleven to 100 hours of practicum and 60 hours of course work, then certified level... two years, two hundred hours of practicum, one hundred hours of coursework....After the certified level you can tutor without a supervisor...Then fellow level, a three-year commitment, 90 hours of course work, practicum. That is what I ended up doing - the fellow level...My role is to keep everyone focused on the literacy components and really breaking it down at every level (Literacy Administrator, School 1).

... around special ed law, what we can and can't do. I think too just because of that lens, that interventionist lens, I might have ideas about different tools or resources that could have an impact on our instructional practices. That would be the area that I would bring expertise (Special Education Administrator. School 1).

I do. It sounds kind of arrogant. I think I was a good teacher but I wasn't an amazing teacher, which is good. There is a teacher that is good [name given]. The joke is $[\mathrm{I} \mathrm{am}]$ the realistic version of [teacher named]. Good but not so good. Also many people here did not teach somewhere else before they came here, including [the superintendent]. So [another team member] and I both taught middle school. My middle school experience has always been helpful. I think that I have been in education longer, in a different state. I have been here 12 years. The fact that I was taking classes, doing PRN - I could refer to other things (Director of Professional Development, School 1). 
The Superintendent in School 1 stated, "I think just history, plus because I am everywhere. That is what my role is. I meet with everybody all the time. Whatever I am saying is coming from different conversation or experiences that I am having." The Director of Social Work in School 1 replied, "Most certainly. Social policy, education policy, clinical social work, evidence-based, school-based behavior intervention.”

In School 2 responses to the question "Do you feel you have specific expertise or knowledge that you bring to the school improvement team?" were similar to those in School 1.

Absolutely. I feel that part of my expertise lies in being part of the community. I grew up in this city, graduated from this high school. I also have, because of my background, my academic background, I bring knowledge of data analysis and survey construction, and I think, more importantly, knowledge of the philosophy of science. I come to those meetings knowing that epistemology lets us know that you shouldn't believe anything just because someone says something, that is just the way things are done (Science Teacher, School 2).

I do. Just though my years of working here and being here so long. I know most of the faculty extremely well. I know a lot of the students. Until they got their chrome books they were constantly in here [the library]. I am good with technology and seeing ways we can use technology to enhance curriculum (Librarian School 2).

The Special Educator stated, "Definitely special education." 
Each participant on the team was able to articulate the expertise that they could bring to the team. That is indicative of the presence of a first step in authentic engagement.

When asked about using research participants also noted an ability to get access to research to further illuminate issues for them as needed. The Literacy Administrator replied, "In my area of expertise I do seek out research.” The Curriculum Director stated, "They [the school improvement team] used research a lot to underscore why we do certain things like project based learning or a certain approach to learning or why intervening with students in a certain way is better than another." The Director of said, "I mean yeah, it sort of depends on what we are looking at. Particularly around literacy. I don't know that much about it. Yeah, [another team member] and I are always just reading something to see what works, what makes sense.” The Superintendent responded similarly stating, "A lot of the work we do we are doing because it is what the research is saying, especially around personalized interventions and real world learning. So, yes." And the Social Work Director replied, "Every step of the way. I need to reference always social policy, ed policy and even my clinical theories and such that drive my work".

Following are the quotes from School 2 on whether they were able to access research to support decision making, they are similar to the comments from members of the school improvement team in School 1. The Special Education Administrator replied, "Hmmm...for instructional things yes. If we are talking about ways to improve instruction, yes, there are places I have done research, around RTI, Reading. I have done a lot of research around how that works. Instructionally yes." The Science Teacher stated, 
"I do...When we talked about...[accreditation] I sought out what they put out, what other schools were working on just to educate myself...I have done my own research to look at what are other people are doing and how is it relevant to what we are doing." The Superintendents' response was similar stating, "We do. I will share whatever grant we have written so they see everything we have written and you know when you write a grant you need to include all the evidence and sources attached." The Principal stated, "For the grading system we are using [a consultant] who has worked with ninety schools across five states and will help us pull in samples of schedules that are more of a hybrid..."

The Impact of Outside Forces on Authentic Engagement and Collaborative Governance Finally, it is important to point out the large role that the state department of education had in meeting discussions, due to regulations and requirements. However, state departments were not physically at the table to discuss these requirements and build consensus. Interview statements, as I noted, under the findings in research question one, made it clear that these outside requirements could make it more difficult for the team to feel that they were reaching authentic consensus. These requirements can also drive discussions, rather than the participants choosing the topics of focus. This was pointed out by many team members when discussing state requirements, as was identified in quotes presented under question 1.

Following are the key findings for the final research question. 
Table 7. Summary of the cross-case findings related to authentic engagement, adaptive leadership and/or collaborative governance.

\begin{tabular}{|l|l|}
\hline$\#$ of findings & discreet findings \\
\hline$\# 1$ & $\begin{array}{l}\text { There was no cross case evidence of authentic engagement, adaptive leadership } \\
\text { and/or collaborative governance. However, following are the findings using this lens: }\end{array}$ \\
\hline $\begin{array}{l}\text { School leaders, faculty and staff who participated on the team had connections to } \\
\text { natural networks in their functional area of expertise and often sought to } \\
\text { informally represent those perspectives as well as their own without prompting } \\
\text { from group leaders. Participants on both teams made some attempts to reach out } \\
\text { to a broader number of stakeholders within the group they represented or } \\
\text { stakeholder groups not on the team. }\end{array}$ \\
\hline$\# 2$ & $\begin{array}{l}\text { Each participant's time in the profession of teaching, individual unique expertise } \\
\text { and confidence in that expertise, were important parts of how they expressed the } \\
\text { contributions they felt they could make to the team. Team members also often } \\
\text { sought out research to complement that expertise. }\end{array}$ \\
\hline$\# 3$ & $\begin{array}{l}\text { State department of education regulations and accrediting requirements had the } \\
\text { potential to minimize authentic engagement because they influenced decisions and } \\
\text { discussions without being present directly at the table, affecting true consensus. }\end{array}$ \\
\hline
\end{tabular}

\section{Summary of Findings}

In summary, many of the questions in this study were not clearly answered because each school was distinct, approached the school improvement team process, differently, and engaged multiple stakeholders in ways that were very organic to their settings. This, of course, in and of itself, suggests that schools approach school improvement teams in different ways and that multiple stakeholder engagement is an important new area of work for schools. However, despite the different school environments and unique school improvement team cultures, there were evident commonalities found in each of the questions under study. These commonalities focused on struggles to include a broader audience of voices; the importance of consensus-based decision-making to authentic engagement; the influence of state-based requirements; the structure of the meetings themselves as an unnatural format for authentic engagement of multiple stakeholders; and budgetary, data, and technological issues. 
First, based on the question of who is and who is not engaged on the school improvement teams and the reasons for this, the study found that both schools struggled to include the parents, youth, and community voice, as required by legislation on school improvement teams. This was demonstrated, despite having rich engagement opportunities for each of these groups outside the school improvement team meetings. This lack of inclusion of required participants in school improvement team meetings was due to perceived barriers to these groups participating in the rigid structure of these settings. This was technically in violation of school improvement team legislation and the spirit of that legislation that suggests that school improvement efforts will be more effective if they include a broader range of voices, working together toward consensus.

Both schools did, however, include leadership and school staff that included those with expertise in both curriculum and social-emotional areas, including family support/social work staff, curriculum directors, literacy specialists, special educators and the superintendent. Both schools also engaged a broad array of shared stakeholders in other rich ways in the school, outside of the school improvement team. Considering which groups were engaged contributes to an understanding of the definition of stakeholders. These included youth in the school; parents of children in the school; health and human service nonprofits and public agencies; businesses with an interest in providing internships, support and curricular advice; institutions of higher education with schools of education, consultants and researchers with expertise in the field.

The role and influence of the state department of education and accreditation requirements was also noteworthy in this consideration of who was engaged and who was not. Though not a direct participant at meetings, these entities had a large voice at the 
table, and at times, more so than the participants, due to these agencies' state-based educational directives. There were often conflicts between what participants at the meeting wanted to do and what state regulations required. In some team meetings, the state regulations had such an outsized role that they ended up becoming the focus of the meetings.

The second research question looked at which issues the school improvement teams addressed. It was found that the schools shared much in common with respect to the school improvement issues they discussed. It was also clear that these issues are integral to school improvement decision-making, including: curriculum, professional development, student assessment, state department of education and/or accreditation requirements, student behavior interventions, learning personalization/differentiation, and work with outside partners and consultants. School improvement teams have not been studied deeply to date. It is noteworthy that these high schools, with leaders that expressed a high interest in multiple stakeholder engagement in decision-making, and a legislated state mandate for school improvement teams, focused on issues of high importance to school improvement on their school improvement teams. The one area that was not included in discussions was the budget process. The leaders interviewed were clear that goals set out in the meeting could not be accomplished unless the budget was aligned, and yet the budget was not aligned with the school improvement team meetings, setting up a potential conflict for implementation of team recommendations.

Third, the shift from engagement in discussion to consensus-driven decisionmaking was where the schools seemed to struggle the most. Yet this study found that stakeholders only truly felt engaged when they believed the final decisions related to the 
issues they were discussing were made through consensus to the greatest degree possible. Stakeholders were realistic that consensus was not always possible, but they expressed that feeling authentically engaged was their benchmark, and was connected to when consensus was sought and achieved. Consensus appears to be required in the legislation, though the language in the legislation is somewhat vague in that it refers to the teams assisting in the "preparation" and "evaluation" of plans. An important and connected consideration is that team members expressed that they felt they had significant experience to bring to the discussion and often did their own research to enhance their knowledge of a particular topic area. Aside from the requirements of the legislation, without any prompting regarding the role of consensus-driven decision-making, team participants in interviews clearly indicated that consensus was a core element to feeling that their engagement had any authentic meaning for them.

Fourth, while the study found that each school struggled in its own way to achieve this consensus-driven effort with all the stakeholders outlined in the legislation, both schools cited the formal structure of the school improvement team, which had many elements in common at both schools, as an unnatural environment in which to engage student, parent, and community voice. I am using the term "unnatural environment" to capture the many comments made by participants that parents, youth, and other stakeholders would feel uncomfortable in these environments for various reasons. As a result, team members and leaders instead relied on very loose and informal efforts to connect either their own natural networks, their own research efforts, or other stakeholder engagement efforts outside the team to decision-making on the team. Many stakeholders were richly engaged in other ways in the school, and it was often also noted by team 
members that it was a goal to bring back their ideas to the school improvement team. This exchange was not formal, however, and was not observed to be happening in a clear way in meeting discussions. A connected consideration is that both schools had some level of facilitation provided by a leader in the school, rather than outside facilitation. In addition, both schools shared similar team meeting structures including

- meetings that took place around a table during the school day or right after school ended with school professionals,

- an agenda that was created and facilitated by a school leader,

- opportunities for other key decision makers to have input into the agenda,

- discussions among team members regarding issues on the agenda,

- limited opportunities to follow up on meeting discussions outside of meetings,

- and the ability at the end of the meeting to raise new issues for consideration.

Fifth, both schools also faced challenges using student assessment data to support decision making, though both endeavored to do so. There were many conversations held about the importance of using data to better understand how students might be struggling but there was confusion about when to have this conversation on the whole-school-level versus the classroom-level, what data to look at to make the best decisions, which data sets would be most useful, and even when to look at the data and when and how to act on the data. Some of this was driven by required state testing and the availability of those data. However, it was also driven by tests the schools had chosen to use as well. There 
seemed to be no question that student assessment data was important to the discussion, it was rather a matter of confusion around how to use data most effectively.

Finally, there was a small but interesting finding regarding the use of technology for information-sharing among stakeholders. Both schools were working toward using technology more effectively to share information, to jointly edit and produce documents, and to become more creative and efficient in soliciting feedback from larger groups. It became clear in group discussions that team members felt that there was tremendous potential for technology to support engagement efforts. However, there was also confusion expressed at meetings at various times, highlighting the idea that this is still a nascent undertaking and somewhat of a challenge for schools currently. 


\section{CHAPTER 5: IMPLICATIONS}

In considering the implications of the findings for the field, it is important to remember how these cases were chosen. The schools were chosen for study because they already had leaders with a strong interest in multiple stakeholder engagement and already had rich engagement efforts with parents, youth, and community underway in their schools. The schools both operated in racially, ethnically and socioeconomically diverse communities with student populations that reflected those communities. They also had school improvement teams underway that could be studied. Despite these commonalities, the two schools had contrasting educational models, different approaches to the school improvement team, and different internal structures at play. For example, School 2 had a strong teachers' union and School 1 did not have a union in place. However, what is most interesting is that despite these differences, clear commonalities existed across the two school environments that contribute to this emerging field of research and suggest a need for future study and practice. It my hope that schools seeking to implement multiple stakeholder engagement efforts, including, but not limited to school improvement teams, will find some of these findings to be helpful in their environment.

To review, I believe in the power and importance of multiple stakeholder engagement and I share that belief with other modern thinkers in the field (Boykin \& Noguera, 2011; Brown University Lipsitt-Duchin Lecture in Child and Youth Behavior and Development, 2013; Comer, 2004; Epstein, 2011). While the school improvement teams I studied were not effective in meeting the stated goals of the legislation in multiple stakeholder engagement, it was not because the undertaking itself was not worthwhile. It was because the undertaking was so challenging. It is my hope that this 
research further identifies potential strengths as well as challenges to help to identify ways that schools can shape this undertaking as they move forward.

Some implications that I feel are most relevant for further research and for school improvement are offered here.

Further defining the potential stakeholders

One of the first implications identified in this study is an understanding of which groups might comprise multiple stakeholder engagement, or family, school community partnerships, in particular groups that might be included in the definition of "community" in schools. I noted in the literature review that community has not been defined in much detail in the research to date (Epstein, 2011). I chose the schools for study in part for the leaderships' interest in multiple stakeholder engagement, as well as the state-mandated requirement. Therefore, the implication of who was identified as participating in school improvement teams, as well as who was engaged in rich feedback efforts in other ways outside of the school improvement team, includes a predisposition on the part of school leaders. Through research in those schools, with leaders predisposed to engage multiple stakeholders, I was able to more fully define which stakeholders could comprise the definition of family, school, and community in a high school environment. This is an important step for the field. While not all of the following stakeholders were at the actual school improvement team discussions, they were all noted by those interviewed as having an important voice and being richly engaged in other areas of the school. It was revealed in interviews that some team members assumed that input from those stakeholders not represented on the school improvement team would be brought to the team organically. 
However, this was not observed in meetings. The following stakeholders were identified by leaders and team members at both schools as having an important voice, whether engaged directly in the school improvement team or outside it:

- youth, representative of the racial, ethnic and socioeconomic diversity in the school;

- parents of children at the school, representative of the racial, ethnic and socioeconomic diversity in the school;

- teachers, representative of a wide range of curricular areas;

- librarians;

- social work and family support staff within the schools;

- literacy specialists;

- special educators;

- curriculum directors;

- and professional development directors.

Additionally outside agencies or personnel were also named, which could begin to constitute a definition of "community":

- for-profit businesses in the community interested in providing internships and support to students;

- health and human service nonprofits and public agencies in the community;

- institutions of higher education with schools of education in the community;

- and researchers, consultants and experts in the field.

In addition, the study identified state departments of education, federal regulations and accreditors, as having a strong voice in team discussions despite not being present at 
actual meetings. These outside entities have requirements that schools feel they must abide by because they hold financial sway or credibility sway over educational organizations. Team members revealed in interviews that outside regulators can create barriers to team consensus-building toward school improvement because they are not at the table to participate in the process of coming to consensus - they simply represent a mandate. In the case of School 1, occasionally the goal in team meetings was to figure out how to get around those mandates to meet goals that the team had come to through consensus and that were in conflict with the regulations. In the case of School 2 it was often the case that regulations became the core focus of the content of the meetings as leadership utilized those venues as places to discuss implementation of requirements. It would appear from the research that it would behoove schools to let team members know about these requirements in advance of decision-making so members do not become frustrated later when they find their decisions subverted by outside sources. However, these requirements and outside entities should not drive the conversation entirely. It may also be the case that these outside entities have research backing their requirements; research that would be important to share with the team in advance, to guide their efforts and help to build consensus with these outside entities.

The relevance of issues discussed in school improvement teams to school improvement

Given that I was not able to find specific, recent studies on school improvement teams, I believe that an important implication has also been the cataloging of school issues the school improvement teams focused on at the high school level. It will hopefully help future researchers, as well as schools looking to undertake multiple stakeholder engagement through a school improvement team, as they consider which 
stakeholders may be able to best contribute to which decisions. The core areas of focus for discussion were shared by both school improvement teams. They were the following:

- Curriculum

- Data and Assessment

- Professional Development

- State Department of Education and Accreditation Requirements

Also covered at both schools, though not as central to the discussions, were the following:

- Personalized learning/differentiated learning

- Approaches to student behavior issues

- Work with outside partners and consultants

In addition to being critical to school improvement, improvement in these areas could also benefit from multiple stakeholder engagement. One can imagine an important role that teachers, educational researchers, universities with schools of education, and local businesses could play together in curriculum development - either as experts in specific areas of education, pedagogy in general, and/or in preparing students for skills needed for the workforce. One could also imagine that parents, youth, and health and human service partners might have something valuable to add to decision-making about personalized/differentiated learning and student behavior issues. I believe that it is a significant implication to have gained a somewhat greater understanding of the types of decisions that might be covered in a school improvement team in order to make better decisions about who should be engaged in decision-making. 
The budget was one key decision point that leaders at both schools pointed out was not discussed at the school improvement team. The budget was typically set in advance by a different group. Leaders I interviewed at both schools indicated that this could be a barrier to consensus-driven decision-making, since the ability to fund identified solutions for school improvement is critical to moving from decision to implementation. This is an implication for school leaders who are thinking about undertaking multiple stakeholder engagement. It may be important to be up front about the budget constraints or the timing of when solutions can be implemented due to development of the budget. Leaders might also consider connecting the school improvement team process to the budget process more explicitly.

Consensus-driven decision-making - an important element that is difficult to achieve

The research suggests that high schools struggle to engage parents, teachers, youth, and community together in decision-making regardless of their stated interest to engage these groups. This finding is particularly interesting given that it was studied in environments that had other rich, yet "siloed," engagement opportunities for these groups outside the school improvement team. Therefore, for schools that put the resources into the effort, siloed engagement of these groups does not seem to be a challenge. The challenge seems rather how to engage these groups in multiple stakeholder, consensusdriven decision-making across stakeholder groups. No formal structures had been created for including each of the siloed voices in the final decision in the consensus-driven way that my theoretical framework was leading me to look for, and that those interviewed indicated was important to engagement. Those interviewed stated clearly in a variety of 
ways that they do not want simply to have input and a voice, they want to know that their voice is likely to impact how decisions are made. This indicates that consensus-driven decision-making matters. Simply having an agenda, providing opportunities for feedback, even reaching out beyond the team for more feedback, or establishing subcommittees to dig more deeply into an issue, will not matter if participants feel that leadership has, for the most part, already made up their minds.

The belief that this consensus-driven approach is the ideal one for multiple stakeholder engagement was confirmed by interviewee statements. The research showed that team members felt either engaged or disengaged in the work of the school improvement team based on the degree to which they felt the decisions were consensusbased. However, consensus-driven decision-making was difficult for leaders to achieve across different stakeholder groups. They were often able to bring distinct groups together to give them voice but this only translated to vague descriptions of leadership taking teams' ideas under advisement. There was not a clear, focused vision for how consensus would be built among the different stakeholder groups and with leadership. Ideally future research could include action research and other forms of research that identifies opportunities to connect larger natural networks to smaller decision-making bodies. Technology could also potentially play a role as a way to engage large groups in discussions without the constraints of meeting rooms and meeting times.

\section{Future Research}

Identifying and formally recognizing the expertise of different stakeholders 
I found in this study that the team members, all of whom were school staff, were very clear about their areas of expertise and felt extremely knowledgeable. However, they did not always feel accommodated to contribute at a high level. Follow-up research to this study could possibly focus on identifying the expertise of different stakeholder groups relative to key school improvement goals. Clarifying the expertise of individual stakeholders could make the process of consensus decision-making more productive with each member contributing from their specific area of expertise to the correct decision areas rather than trying to speculate on areas where they do not have sufficient knowledge or information. Cataloging the expertise that parents, youth, businesses, nonprofits, public agencies, schools of education and other community partners could bring to the table could help schools considering how to best engage multiple stakeholders.

Natural networks and school improvement team structure Many team participants felt that they brought the ideas from their natural networks to the table - typically those in their functional discipline. I also found many examples of deep and purposeful engagement with parents, businesses, students, nonprofits, universities and educational researchers happening outside the realm of the school improvement team, and team members, to some degree, believed that they were bringing that information back to the team. However, there was no clear, formalized pathway from those groups to the school improvement team, and the individual bringing the ideas sometimes was not a representative of that group. The team structure was noted by various participants as not being conducive to the engagement of different types of 
stakeholders. This was particularly highlighted for parents and youth. Again, there is the opportunity to study or pilot opportunities to connect these natural networks to more purposeful decision-making.

Although I chose not to use social constructivism as a framework for conducting this study, nor communities of practice as a theoretical framework, it could be important to learn more about these natural networks or practices, using those lenses to see how natural networks might connect to decision-making processes. It is impractical to have hundreds of people attending meetings together. Much can be explored and learned about how to move from broad participation in successful student, parent, business, teacher, university, researcher, and public and nonprofit agency engagement efforts to small group final decision-making that takes these multiple perspectives into account and builds consensus, possibly in continuous feedback loops. Looking more deeply at communities of practice in schools for engaging parents, students, teachers and community groups would be a good next step in the research. A possible goal for future research could be identifying how these natural networks might tie back to final decisionmaking bodies, rather than hoping it will trickle in or relying on one or two members of a group, such as parents, to represent the voice of all parents.

\section{Facilitation}

Given the complexity of multiple stakeholder engagement and the sometimes different points of view of leadership, teachers and other stakeholders, it might be worthwhile to explore in future studies whether an outside expert could better facilitate consensus-driven decision-making and authentic engagement. As pointed out in the literature, both the Comer (2004) and Epstein (2011) models have highly designed 
frameworks, which include engaging outside facilitators and consultants trained in the application of the frameworks in schools. These models both had confirmation from outside researchers that these models were effective. This was in contrast to the limited research into more organic school efforts in multiple stakeholder engagement (where schools devised their own methods), which this literature review shows is not as likely to be successful. This study seems to bolster that research. In School 1, I found strong camaraderie, facilitation, and consensus-driven decision-making. However, this was with a fairly homogenous group of stakeholders - all leaders and administrators in the school. In School 2 there were more stakeholders, inclusive of teachers and teachers' union representatives, yet this environment was tense and unproductive, and neither participants nor leaders felt it was conducive to consensus driven decision-making. Both Schools 1 and 2 were missing the parent, youth, and community voice that was called for in the legislation. And in both schools, despite the different cultures, the meetings were run in relatively the same fashion in terms of having an internal facilitator who represented leadership in the school, fixed agendas, meetings around a conference table during or right after school hour. It would seem that people have a fixed idea of how a meeting is run and that does not vary greatly even when the culture and team structure varies. Perhaps outside facilitation with expertise could have made the omissions of key stakeholders more apparent and helped to develop appropriate structures for inclusion. The limited research identified in this literature review on this issue also revealed that the challenge with outsiders was to ensure that in-school stakeholders still felt ownership of the process and that the engagement process felt organic to the school culture. This 
question of outside facilitation or whether resources could be developed within the school for appropriate facilitation might be an important area for future research.

\section{Technology}

The school improvement teams studied were looking at, and beginning to integrate, ways to use technology to make better multiple stakeholder decisions. This is not surprising perhaps given that currently school districts are hiring technology experts alongside upper administration, representing a shift in the resource priorities in schools. There appears to be potential for the role of technology in multiple stakeholder engagement in decision-making, based on the ways that the groups were already considering its use. Some things to be considered in future research include:

- the role of technology in information sharing across large groups,

- the role of technology in engaging a more diverse range of voices in discussion,

- the role of surveys in providing voice to a larger group in decision making processes,

- the role of online communication tools could play in authentic engagement practices.

Using research-based data to inform multiple stakeholder decision-making

Another area for future research that emerged is the role of sources of trustworthy research and data. Both schools attempted to use student assessment data but struggled in different degrees about how to connect student assessment to school improvement. Both schools also brought in researchers and consultants to help them tackle difficult 
decisions. One goal for future study might be to look at the role that trustworthy research plays in building consensus. Another goal for future research could be to look at how the expertise of those within the school or on the team is viewed. For example, there could be a question about the role of parent and student voice versus teacher voice in developing curriculum. Teachers may have spent years studying appropriate curriculums, yet students and parents may have insight into which curriculum engages them sufficiently with the material and supports their desire to learn. In addition, outside consultants working with leadership may have cutting-edge research into curriculum to bring to the discussion. Researchers could study which point of view garners merit when leaders are looking at making decisions.

\section{CONCLUSION}

The goal of this study was to describe richly the school improvement team processes of two schools in the Northeast region that already had a stated commitment by leadership to multiple stakeholder engagement. As a researcher, I sought answers to the questions of who was engaged on the teams, how they were chosen, how they were engaged, and what decisions they were engaged in. The goal was also to look at facilitation of these meetings; other multiple stakeholder engagement efforts in the school that might be connected to the school improvement teams; and to view the teams through the lens of authentic engagement, collaborative governance and adaptive leadership.

Although there were some limitations to this study, common findings were discovered across two schools with very different school models and distinct school improvement team structures. Given that the field of research into school, parent, and 
community partnerships, when looking at multiple stakeholder engagement in decisionmaking in particular, has been limited, the findings from this study are significant and will fill a gap in the research. It is also my hope that it will be of some value to current school improvement teams. The area of multiple stakeholder engagement in decisionmaking is an important area for future research. There have been many calls in recent years for schools to increase stakeholder engagement. One outgrowth of that has been the development of school improvement teams, and even legislation in some states, requiring school improvement teams that engage multiple stakeholders in decision-making. As a result, school improvement teams have become increasingly common, typically with a goal of bringing together multiple stakeholders to provide input into decision-making for school improvement. However, there has been little research on the make-up of these teams and of other multiple stakeholder engagement efforts. The task of engaging all these voices will likely continue to be an important one for $21^{\text {st }}$ century public schools, requiring more attention and focus on how to best accomplish this challenging work. 


\section{APPENDIX A}

Rhode Island College and The University of Rhode Island

Department of Education

Studying School Improvement Teams to Analyze Multiple Stakeholder Engagement in Decision Making in Public Education

\section{CONSENT FORM FOR RESEARCH}

You have been asked to take part in a research project described below. The researcher will explain the project to you in detail. You should feel free to ask questions. If you have more questions later, Julie DiBari, the person mainly responsible for this study, 401-248-4985, or her faculty advisor, Marie Lynch, PhD, 401-954-2342 or mlynch@ric.edu will discuss them with you. You must be at least 18 years old to sign this form. If you are a minor you will need the consent of a parent.

Description of the project:

You have been asked to take part in this research that is studying school improvement teams to analyze multiple stakeholder decision-making in public education. The primary focus of this proposed research study will be on how at least 2 high schools engage multiple stakeholders in decision making on school improvement teams, emphasizing who the schools include, and why they engage these stakeholders in the ways that they do.

What will be done:

If you decide to take part in this study here is what will happen: the researcher will observe and record each meeting of the school improvement team and develop findings from these observations. The observations will take place over the course of one school year. The researcher will also interview you individually in person. The interview will take one and one half hours with the potential for a follow up interview by phone or in person if needed for clarification.

Benefits of this study:

Although there will be no direct benefit to you for taking part in this study, the researcher may learn more about multiple stakeholder engagement in decision making on school improvement teams, which could benefit the field of education.

Risks or discomfort:

No risk or discomfort to you is expected as a result of this study.

If you think you were treated unfairly or would like to talk to someone other than the researcher about your rights or safety as a research participant, please contact Dr. Christine Marco, Chair of the Rhode Island College Institutional Review Board at IRB@ric.edu, or by phone at 401-456-8598, or by writing to Dr. Christine Marco, Chair 
IRB; c/o Department of Psychology, Horace Mann Hall 311; Rhode Island College; 600 Mount Pleasant Avenue; Providence, RI 02908.

\section{Confidentiality:}

Your part in this study is confidential. None of the information will identify you by name. All records will be maintained in a locked cabinet and destroyed within three years after the study is completed.

Decision to quit at any time:

The decision to take part in this study is up to you. You do not have to participate. If you decide to take part in the study, you may quit at any time. Whatever you decide will in no way penalize you. If you wish to quit, simply inform Julie DiBari, 401-2484985 , of your decision.

Rights and Complaints:

If you are not satisfied with the way this study is performed, you may discuss your complaints with Julie DiBari, 401-248-4985, confidentially, if you choose. In addition, you may contact Julie's Faculty Advisor, Marie Lynch, PhD at 401-9542342 or mlynch@ric.edu or Dr. Christine Marco, Chair of the Rhode Island College Institutional Review Board at IRB@ric.edu, or by phone at 401-456-8598, or by writing to Dr. Christine Marco, Chair IRB; c/o Department of Psychology, Horace Mann Hall 311; Rhode Island College; 600 Mount Pleasant Avenue; Providence, RI 02908.

You have read the Consent Form. Your questions have been answered. Your signature on this form means that you understand the information and you agree to participate in this study.

I __agree __do not agree to be audiotaped for this study.

$\overline{\text { Signature of Participant }} \quad$ Signature of Researcher

$\overline{\text { Typed/printed Name }} \quad$ Typed/printed name

Date

Date

Please sign both consent forms, keeping one for yourself 


\section{APPENDIX B}

\section{Interview Tools}

\section{Interview Tool One - for school improvement team members}

Interviewer statement to participant "I am researching how schools engage a large number of different stakeholders (such as parents, teachers, businesses, nonprofits, social service agencies). Specifically I am interested in how they are involved in decision making in the school. I am looking at School Improvement Teams specifically as a vehicle for engagement and I want to describe what that looks like and why it functions the way it does this particular school, with a goal of ultimately identifying themes across three schools that I am looking at"

Informal question 1: I would like to start out by just having you tell me a little bit about yourself and your role in the school.

Informal question 2: Can you tell me about the School Improvement Team from your perspective?

Structured and Semi-Structured Question Section ("I will use why do you think that is true" Or "tell me more about that" to probe further on some of these questions)

1. What is the role of the School Improvement Team in the school from your perspective?

2. How closely would you say the team follows its mission statement (if it has one researcher can read mission statement to interviewee if needed)

3. What group do you represent on the school improvement team?

4. Please tell me about how you are engaged in the work of the school improvement team. (probe for examples)?

5. Do you feel you have specific expertise or knowledge that you bring to the school improvement team?

6. When participating in decision making how do you feel your particular expertise is recognized by the group? 
7. To what extent are you able to understand the issues the school improvement team is addressing?

8. Do you use research to help you understand issues?

9. How are you supported in your role?

10. How does the school improvement team's work impact decision making in the school?

11. How does your role specifically support the team's decision making?

12. Do you represent yourself only on the team or the larger stakeholder group that you represent?

a. (if response is larger group) - How are you able to do that?

13. Please describe the overall process the school improvement teams use for engaging multiple stakeholders in decision making.

14. Are there any formal elements to this process that you have not yet described?

15. Where does the responsibility for managing relationships among team members lie?

16. How does the group leader manage input from everyone?

17. Where does the ultimate responsibility for final decision making lie?

18. What types of decisions is the school improvement team engaged in?

19. Do you participate in all activities of the team or certain activities?

20. Please describe which school improvement team activities you participate in.

21. How are different the different groups represented on the team engaged -i.e. teachers, parents, nonprofits, businesses (together or separately)? 
22. Is the school improvement team connected to any other efforts within the school to engage other stakeholders in decision making?

23. Can you describe those other efforts if you are familiar with them?

24. Can you describe the relationship among members of the school improvement team?

25. Can you describe your Q15relationship with other team members?

26. Can you describe your team's relationship generally with the decision makers in the school?

27. Can you describe your relationship with the decision makers in the school?

Final informal question: What haven't I asked that I should know about the School Improvement Team?

\section{Interview Tool Two - for key decision makers - principal and superintendant}

Interviewer statement to participant "I am researching how schools engage a large number of different stakeholders (such as parents, teachers, businesses, nonprofits, social service agencies). Specifically I am interested in how they are involved in decision making in the school. I am looking at School Improvement Teams specifically as a vehicle for engagement and I want to describe what that looks like and why it functions the way it does this particular school, with a goal of ultimately identifying themes across three schools that I am looking at"

Informal question 1: I would like to start out by just having you tell me a little bit about yourself and your role in the school.

Informal question 2: Can you tell me about the School Improvement Team from your perspective?

Structured and Semi-Structured Question Section ("I will use why do you think that is true" Or "tell me more about that" to probe further on some of these questions) 
1. What is the role of the school improvement team in the school from your perspective?

2. How closely would you say the team follows its mission statement (if it has oneresearcher can read mission statement to interviewee if needed)

3. Can you describe your interactions with the school improvement team (probe for examples)

4. When engaging with the school improvement team how do you feel your particular expertise is recognized by the group?

5. To what extent do you think the members understand the issues the school improvement team is addressing?

6. Do you use research to help the team understand issues?

7. How does the school support school improvement team members in their role?

8. How does the school improvement team's work impact decision making in the school?

9. Can you describe how the school improvement team impacts decisions you make personally, if at all? (probe for examples)?

10. Are their any constraints on the school improvement team's ability to support decision making?

11. Please describe the overall process the school improvement team uses for engaging multiple stakeholders in decision making.

12. Are there any formal elements to this process that you have not yet described?

13. Where does the responsibility for managing these relationships among members of the school improvement team lie? 
14. How does the group leader manage input from everyone?

15. Where does the ultimate responsibility for final decision making lie?

16. What types of decisions is the school improvement team engaged in?

17. Do you participate in all activities of the team or certain activities?

18. Please describe which school improvement team activities you participate in.

19. How are different stakeholder groups engaged - i.e. parents, teachers, businesses, youth (ask about together or separately)?

20. Is the school improvement team connected to any other efforts within the school to engage other stakeholders in decision making?

21. Can you describe those other efforts if you are familiar with them?

22. Can you describe the relationship among school improvement team members?

23. Can you describe your relationship with school improvement team members?

24. Can you describe the team's relationship generally with the decision makers in the school?

25. Can you describe your relationship with other decision makers?

Final informal question: What haven't I asked that I should know about the School Improvement Team? 
APPENDIX C

TABLE FOR TRACKING PROPOSITIONS

\section{Unit of analysis - School Student Improvement Team}

Framework for Observations and Coding Interviews

\begin{tabular}{|l|l|l|l|l|l|}
\hline & $\begin{array}{l}\text { Case } \\
\text { Study } 1\end{array}$ & $\begin{array}{l}\text { Case } \\
\text { Study 2 }\end{array}$ & $\begin{array}{l}\text { Case } \\
\text { Study 3 }\end{array}$ & $\begin{array}{l}\text { Cross Case } \\
\text { Themes }\end{array}$ & Notes \\
\hline Authentic Engagement & & & & & \\
\hline $\begin{array}{l}\text { How do participants } \\
\text { understand their role on } \\
\text { the team? }\end{array}$ & & & & \\
\hline $\begin{array}{l}\text { How do participants } \\
\text { understand their expertise } \\
\text { relative to other } \\
\text { participants? }\end{array}$ & & & & & \\
\hline $\begin{array}{l}\text { How are/are participants } \\
\text { given the opportunity to } \\
\text { reflect and access to } \\
\text { research related to their } \\
\text { concerns? }\end{array}$ & & & & \\
\hline $\begin{array}{l}\text { How are/Are participants } \\
\text { given an understanding of } \\
\text { how their engagement will } \\
\text { impact decision making? }\end{array}$ & & & & & \\
\hline $\begin{array}{l}\text { Collaborative Governance } \\
\text { and Collective Impact }\end{array}$ & & & & \\
\hline $\begin{array}{l}\text { To what degree are } \\
\text { participants representing } \\
\text { their larger stakeholder } \\
\text { group? }\end{array}$ & & & & & \\
\hline $\begin{array}{l}\text { What types of decisions are } \\
\text { stakeholders engaged in } \\
\text { and why? }\end{array}$ & & & & & \\
\hline $\begin{array}{l}\text { How does the school define } \\
\text { the role of the school } \\
\text { improvement team and } \\
\text { why? }\end{array}$ & & & & & \\
\hline $\begin{array}{l}\text { Where does the ultimate } \\
\text { responsibility for final } \\
\text { decision making lie? }\end{array}$ & & & & \\
\hline $\begin{array}{l}\text { Are decisions driven by } \\
\text { consensus? }\end{array}$ & & & & \\
\hline $\begin{array}{l}\text { What, if any, tensions exist } \\
\text { between and among team } \\
\text { members? }\end{array}$ & & & & \\
\hline $\begin{array}{l}\text { How is rapport built among } \\
\text { team members? }\end{array}$ & & & & \\
\hline Are there shared goals & & & & \\
\hline
\end{tabular}




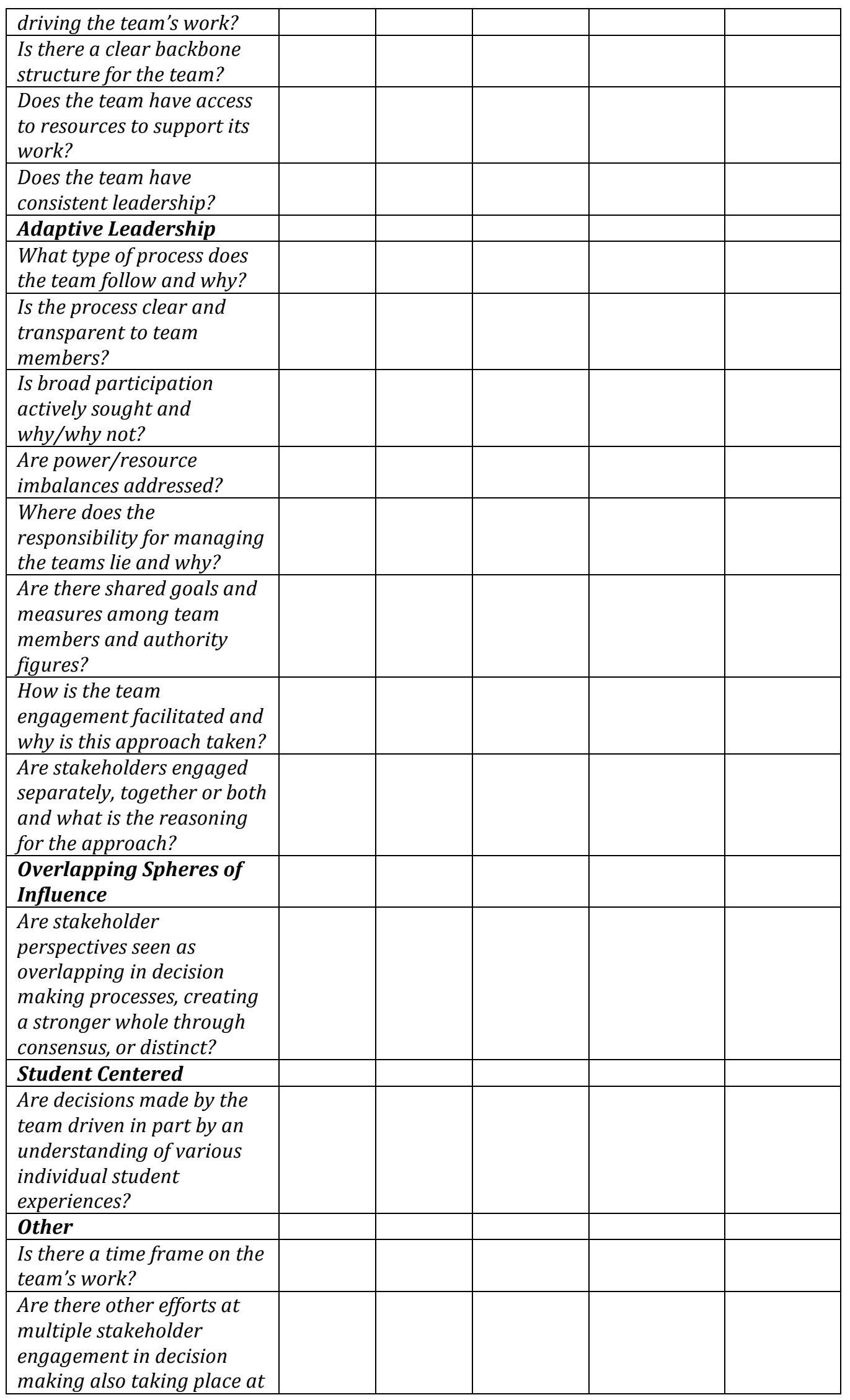




\begin{tabular}{|l|l|l|l|l|l|}
\hline the school? & & & & & \\
\hline $\begin{array}{l}\text { - ifyes - How are the SITS } \\
\text { connected to these other } \\
\text { stakeholder engagements } \\
\text { efforts? }\end{array}$ & & & & & \\
\hline & & & & & \\
\hline & & & & & \\
\hline $\begin{array}{l}\text { What are the evident } \\
\text { strengths of the SITS in } \\
\text { multiple stakeholder } \\
\text { engagement? }\end{array}$ & & & & & \\
\hline $\begin{array}{l}\text { What are the evident } \\
\text { weaknesses of the SITs in } \\
\text { multiple stakeholder } \\
\text { engagement? }\end{array}$ & & & & & \\
\hline $\begin{array}{l}\text { What other themes } \\
\text { emerge? }\end{array}$ & & & & & \\
\hline
\end{tabular}


APPENDIX D

STAKEHOLDER TRACKING FORM

Unit of analysis - School Student Improvement Team

Analysis tool to look at types of stakeholders engaged, types of engagement, and intersection

\section{Look at individual cases first and then look for themes across cases}

(H=High, M=Medium, L=Low, $N=$ Not Evident)

\begin{tabular}{|l|l|l|l|l|l|l|}
\hline $\begin{array}{l}\text { Type of } \\
\text { Stakeholder }\end{array}$ & $\begin{array}{l}\text { School } \\
\text { Engagement } \\
\text { with } \\
\text { Stakeholder } \\
\text { (H/M/L/N) }\end{array}$ & $\begin{array}{l}\text { Authentic } \\
\text { Engagement } \\
\text { (H/M/L/N) }\end{array}$ & $\begin{array}{l}\text { Collaborative } \\
\text { Governance } \\
\text { and Collective } \\
\text { Impact } \\
\text { (H/M/L/N) }\end{array}$ & $\begin{array}{l}\text { Adaptive } \\
\text { Leadership } \\
\text { (H/M/L/N) }\end{array}$ & $\begin{array}{l}\text { How } \\
\text { group is } \\
\text { defined }\end{array}$ & $\begin{array}{l}\text { Notes - } \\
\text { Other } \\
\text { Key } \\
\text { Findings }\end{array}$ \\
\hline Teachers & & & & & & \\
\hline Parents & & & & & & \\
\hline Students & & & & & & \\
\hline Businesses & & & & & & \\
\hline $\begin{array}{l}\text { Department } \\
\text { Heads }\end{array}$ & & & & & & \\
\hline $\begin{array}{l}\text { School social } \\
\text { workers }\end{array}$ & & & & & & \\
\hline $\begin{array}{l}\text { Guidance } \\
\text { counselors }\end{array}$ & & & & & & \\
\hline School nurse & & & & & & \\
\hline $\begin{array}{l}\text { Nonprofit - } \\
\text { Youth } \\
\text { development }\end{array}$ & & & & & & \\
\hline $\begin{array}{l}\text { Nonprofit - } \\
\text { Health }\end{array}$ & & & & & & \\
\hline $\begin{array}{l}\text { Nonprofit - } \\
\text { Community } \\
\text { voice }\end{array}$ & & & & & & \\
\hline $\begin{array}{l}\text { Nonprofit - } \\
\text { other }\end{array}$ & & & & & & \\
\hline $\begin{array}{l}\text { Department } \\
\text { of Social } \\
\text { Services }\end{array}$ & & & & & & \\
\hline $\begin{array}{l}\text { Department } \\
\text { of Human } \\
\text { Services }\end{array}$ & & & & & & \\
\hline $\begin{array}{l}\text { Public Health } \\
\text { Department }\end{array}$ & & & & & & \\
\hline $\begin{array}{l}\text { Educational } \\
\text { Researchers }\end{array}$ & & & & & & \\
\hline Others & & & & & & \\
\hline
\end{tabular}




\section{APPENDIX E \\ FORM FOR TRACKING CODES}

Unit of analysis - School Student Improvement Team

\section{Coding - Listing Key Themes that Emerge through Coding from Interviews, Observations and Documents}

\begin{tabular}{|l|l|l|l|l|}
\hline $\begin{array}{l}\text { Key Themes that } \\
\text { Emerged Through } \\
\text { Coding }\end{array}$ & Case Study 1 & Case Study 2 & Cross Case Themes & Notes \\
\hline & & & & \\
\hline & & & & \\
\hline & & & & \\
\hline & & & & \\
\hline & & & & \\
\hline & & & & \\
\hline & & & & \\
\hline & & & & \\
\hline & & & & \\
\hline
\end{tabular}




\section{BIBLIOGRAPHY}

American Educational Research Association. (2012) The idea of a public education: Education, democracy and the public good. Washington, D.C.: Review of Research in Education. Volume 36.

Ansell, C. and Gash, A. (2007) Collaborative governance in theory and practice. Journal of Public Administration Research and Theory, Inc. Oxford: England: Oxford University Press.

Apple, M. (2008). Curriculum planning: Content, form and the politics of accountability. The SAGE Handbook of Curriculum and Instruction. New York: SAGE Publications.

Arriaza, G. (2004) Making changes that stay made: School reform and community involvement. The High School Journal. Chicana/o Activism in Education: Theories and Pedagogies of Transformation, Vol. 87, No. 4, pp. 10-24. . pp. 1024. North Carolina: University of North Carolina Press.

Barnes, F. (2004). Making school improvement part of daily practice. Annenberg Institute for School Reform. Providence, RI: Brown University.

Ben-Avie, M; Comer, J.; Joyner E;. (2004). Transforming school leadership and management to support student learning and development: The field guide to Comer schools in action. Thousand Oaks, CA: Corwin Press.

Biesta, J.J. and Burbules, N. (2003). Pragmatism and educational research. New York: Rowman and Littlefield Publishers, Inc.

Borman, G. et al. (2000). Four models of school improvement: Successes and challenging in reforming low-performing, high performing, high poverty Title I schools. Memphis, TN: Johns Hopkins University and University of Memphis. Report No. 48

Boykin, A.W. and Noguera, P. (2011). Creating the opportunity to learn. Alexandria, VA: ASCD.

Bloomberg Business Week. (2013) How to fix the education crisis. Retrieved October 15, 2001 from http://www.businessweek.com/magazine/how-to-fix-the-educationcrisis-10132011.html

Brantinger, E. (2003). Dividing classes: How the middle class negotiates and rationalizes school advantage. NY: Routledge/Falmer.

Brill, S. (2011) Class warfare: Inside the fight to fix America's schools. New York: 
Simon \& Schuster Paperbacks.

Brown University Lipsitt-Duchin Lecture in Child and Youth Behavior and Development. (2013). Reflections on race, child development and school reform. Presented by Brown University and Rhode Island Kids Count. Comments made by James Comer.

Bryk, A.S. (2002). Trust in schools: A core resource for improvement. New York, NY: Russell Sage Foundation Publications.

Bryk, A.S., Sebring, P.B., Allensworth, E., Luppeascu, S., \& Easton, J. Q. (2010).Organizing schools for improvement: Lessons from Chicago. Chicago, IL: University of Chicago Press.

Charmaz, K. (2006). Constructivist grounded theory: A practical guide through qualitative analysis. Thousand Oaks, CA: SAGE Publications.

Cohen, J., Guffy, S., Higgins-D'Allesandro, A. Thapa, A. (September 2013). A review of school climate research. Review of Educational Research, Vol. 83, No. 3. p. 357385. Washington, D.C.: American Educational Research Association.

Comer, J.; Haynes, N; Joyner E; Ben-Avie, M. (1996). Rallying the whole village: The Comer process for reforming education. Teachers College Press. New York, NY: Columbia University.

Comer, J. (2004). Leave no child behind: Preparing today's youth for tomorrow's world. New Haven, CT: Yale University Press. Commonwealth of Virginia Department of Education. (2014). Superintendent's Memo \#286-12. Retrieved on May 9, 2014 at http://www.doe.virginia.gov/administrators/superintendents_memos/2012/286 $12 . \operatorname{shtml}$

Cook, T.; Habib, F-N.; Phillips, M.; Settersten, R.; Shagle, S. and Degirmencioglu, S. (1999). Comer's school development program in Prince George's County, Maryland: A theory- based evaluation. Washington, D.C.: American Educational Research Journal, Vol. 36, No. 3, pp. 543-597.

Cook, T.; Murphy, R.; and Hunt, D. (2000). Comer's school development program in Chicago: A theory-based evaluation. Washington, D.C.: American Educational Research Journal, Vol. 37, No. 2, pp. 535-597.

Corcoran, M., et al. Collective impact for opportunity youth. FSG. Washington DC. Retrieved on October 12, 2013 http://www.fsg.org/tabid/191/ArticleId/735/Default.aspx?srpush=true

Dewey, J. (1997a). Democracy and education, New York: Free Press. 
Dewey, J. (1997b). Experience and education. Cambridge, MA: Harvard University Press.

Education News (2016). American education: An origin story. Retrieved on April 14, 2016 at http://www.educationnews.org/education-policy-and-politics/americanpublic-education-an-origin-story/

Epstein, J. (2005). A case study of the partnership schools comprehensive school reform (CSR) model. The Elementary School Journal, Vol. 106. No. 2. pp. 151-170. Chicago, IL: University of Chicago Press.

Epstein, J. (2011) School, family and community partnerships: Preparing educators and improving schools. Boulder, CO: Westview press: Boulder.

Epstein, J.; Galindo, C. and Sheldon, S. (2011). Levels of leadership: Effects of district and school leaders on the quality of school programs of family and community involvement. Educational Administration Quarterly, 47: 462. SAGE Publications.

Feistein, N. (March 2011). Toward a general theory of strategic action fields. American Sociological Association Social Theory Journal, 29:1.

Freire, P. (1993). Pedagogy of the oppressed, 20th anniversary ed. New York: Continuum.

Garcia Bedolla, L. (2012) Latino education, civic engagement and the public good: Education, democracy and the public good. Review of Research in Education. Washington, D.C.: American Educational Research Association. Volume 36. Google (2013). Search term "school improvement teams."

Giroux, H. (2011). On critical pedagogy. New York: Bloomsbury.

Gordon, M. and Seashore Louis, K. (2009). Linking parent and community involvement with student achievement: Comparing principal and teacher influences of stakeholder influence. Chicago, IL: American Journal of Education, Vol 116, No 1, p. 1-31. Journals.

Hanley, F; Brown, J.; Kania, J. and Kramer, M. (2012) Channeling change: Making collective impact work. Stanford Social Innovation Review. 20 Retrieved on April 24, 2014 at http://www.ssireview.org/blog/entry/channeling_change_making_collective_impa ct_work?cpgn $=\mathrm{WP} \% 20 \mathrm{DL} \% 20-\% 20$ Channeling\%20Change

Heck, R. and Hallinger, P. (2009). Assessing the contribution of distributed leadership to school improvement and growth in math achievement. American Educational Research Journal. Washington, D.C.: American Educational Research Association, Vol. 46, No. 3, pp. 659-689. 
Heibert, J. and Stigler, J. (2009). The teaching gap: Best ideas from the world's teachers for improving education in the classroom. New York: Simon and Schuster.

Heifeitz, R., Grashow, A. \& Linsky, M. (2009) The practice of adaptive leadership: Tools and tactics for changing your organization and the world. Cambridge, MA: Harvard Business Press.

Henderson, A. \& Mapp, K. (2002). A new wave of evidence: The impact of school, family and community connections on student achievement. Austin, TX: Southwest Educational Develop Laboratory.

Hope, Max. (2012). The importance of belonging: Learning from the student experience of democratic education. Journal of School Leadership, Volume 22. Institute for a Competitive Workforce. U.S. Chamber of Commerce. About ICW. Who We Are. Retrieved on October 12, 2011 from http://icw.uschamber.com/about-icw

Huberman, M., Miles, M. and Saldana, J. (2014). Qualitative data analysis: A methods sourcebook. Edition 3. New York: Sage Publications.

John Hopkins University. (2013). National Network of Partnership Schools. Retrieved on November 13, 2013 at http://www.csos.jhu.edu/p2000/

James, W. (1991). Pragmatism. Amherst, NY: Prometheus Books.

Kania, J. and Kramer, J. (Winter 2011). Collective Impact. CA: Stanford Social Innovation Review. Retrieved on April 24, 2014 at http://www.ssireview.org/blog/entry/channeling_change_making_collective_impa ct_work?cpgn $=\mathrm{WP} \% 20 \mathrm{DL} \% 20-\% 20$ Channeling\%20Change

Kania, J. and Kramer, M. (2011) Collective Impact. CA: Stanford Social Innovation Review. Winter 2011. 65. Retrieved on April 27, 2014 at http://www.ssireview.org/articles/entry/collective_impact

Kohlberg, L. (1971). Indoctrination versus relativity in education. Zygon 6: 285-310. Chicago, IL: Zygon and University of Chicago.

Kozol, J. (1991). Savage inequalities: Children in America's schools. Broadway.

Kristsonis, A. Comparison of change theories. International Journal of Scholarly Academic Intellectual Diversity. Volume 8. Number 1. 2004-2005.

London, S. Understanding change: How it happens and how to make it happen. (Originally part of a background study for the Pew Partnership for Civic Change) Retrieved November 2012 at http://www.scottlondon.com/reports/change.html 
Louisiana Department of Education. (2010). Tools for success.

Malloy, W. and Rayle, J. (2000) Using the Comer process to create a successful middle school. Middle School Journal, Vol. 31, No. 5, p. 12-18.

Marsh, J. and Wohlstetter, P. (2013). Recent trends in intergovernmental relations: The resurgence of local actors in education policy. Educational Researcher. Washington, D.C. American Educational Research Association, Volume 42: Number 5.

Martin, M., Fergus, E. and Noguero, P. (2010). Responding to the needs of the whole child: A case study of a high-performing elementary school for immigrant children. New York, NY: New York University.

Massachusetts Department of Secondary and Elementary Education (2014) Section 5. Education laws and regulations. Retrieved on May 9, 2014 at http://www.doe.mass.edu/lawsregs/advisory/cm1115gov.html\#VS

Maxwell, Joseph. (Fall 1992) Understanding and validity in qualitative research. Cambridge, MA: Harvard Educational Review: 62, 3; Research Library Core. pg. 279

Merriam, S. (2009). Qualitative research: A guide to design and implementation. San Francisco, CA: Jossey Bass.

Michigan Legislature. (2014). The revised school code (excerpt): Act 451 of 1976. Section 5: School councils and school based decision making. Retrieved on May 9,2014 at http://www.legislature.mi.gov/(S(wo5dth2uoubobj452vexdy45))/mileg.aspx?page $=$ GetObject\&objectname $=$ mcl-380-1277

Midgley, C. \& Wood, S. (1993). Beyond site based management: Empowering teachers to reform schools. The Phi Delta Kappan. Volume 75. No. 3. p. 245,-252.

Miller, R. and Rowan, B. (2006). Effects of organic management on student achievement. Washington, D.C.: American Educational Research Journal, Vol. 43, No. 2, pp. 219-253.

Murphy, Jl, Everston, C, Radnofsky, Mr. (1991). Restructuring schools: Fourteen elementary and secondary teachers' perspectives on reform. The Elementary School Journal, Vol. 92, No. 2, pp. 135-148. Chicago, IL:

The University of Chicago. Models of poverty and planned change: (1976), A framework for synthesis. Kalamazoo, MI: Journal of Sociology and Social Welfare, Vol. V, No. 3. 316-325. 
Nakulla, M. and Toshalis, E. (2012) Motivation, engagement and student voice. Jobs For the Future, Nellie Mae Education Foundation. Retrieved on December 5, 2012 at http://www.studentsatthecenter.org/sites/scl.dldev.com/files/Motivation\%20Enga gement $\% 20$ Student $\% 20$ Voice_0.pdf

Noddings, N. (2013). Democracy and education in the $21^{\text {st }}$ century. New York: Teachers College Press. Columbia University.

Noguera, P. (Spring 2009). The achievement gap: Public education in crisis. New Labor Forum, p. 60-69. Joseph Murphy Institute. New York, NY: City University of New York.

North Carolina General Assembly (2014). G.S. 115C-47G.S. 115C-47. Retrieved on May15, 2014 at http://www.ncleg.net/EnactedLegislation/Statutes/HTML/BySection/Chapter_115 C/GS_115C-47.html

Oklahoma State Department of Education (2014). Oklahoma LEA 1003(g) Application. Retrieved on May 9, 2014 at http://ok.gov/sde/sites/ok.gov.sde/files/SIGOKLEAAppCohort3.pdf

Owens, R. and Valesky, T. (2011). Organizational behavior in education: leadership and school reform. New Jersey: Pearson.

Patton, M-Q. (2002). Qualitative research evaluation methods. Thousand Oaks, CA: SAGE Publications.

The Pew Charitable Trusts. (2011). Philadelphia Research Initiative. Philadelphia's changing schools and what parents want from them. June 2010. Retrieved on October 14, 2011 from www.pewtrusts.org/uploadedFiles/wwwpewtrustsorg/Reports/Philadelphia_Resea rch_Initiative/PRI_education_report.pdf

Pennsylvania State Education Association. (2007). PSEA guide to school improvement planning. Retrieved on May 9, 2014 at https://www.psea.org/uploadedFiles/Publications/Professional_Publications/Infor mational_Publications/LocalSupportGuide.pdf

Public Private Ventures (2011). Priorities for a new decade: Making (more) social programs work (better). Retrieved on May 13, 2014 from http://ppv.issuelab.org/resource/priorities_for_a_new_decade_making_more_soc ial_programs_work_better

Ravitch, D. (2010). The death and life of the great American school system: How testing and choice are undermining education. New York: Basic Books. 
Rhode Island General Assembly. (2011). Rhode Island School improvement team Act. Chapter 16-53.1-2. Establishment of school improvement teams. Retrieved on August 11, 2011 at http://webserver.rilin.state.ri.us/Statutes/title16/1653.1/INDEX.HTM

Rogers, J., Mediratta, K., Shah, S. (2012). Building power, learning democracy: Youth organizing as a site of civic development. Education, democracy and the public good. Review of Research in Education. Washington, D.C.: American Educational Research Association. Volume 36.

Rothstein, R. (2013). For public schools, segregation then, segregation since: Education and the unfinished march. Washington, D.C.: Economic Policy Institute.

Saldana, J. (2013). The coding manual for qualitative researchers. $2^{\text {nd }}$ Edition. London: SAGE Publications.

Sanders, M. (1996). School--family--community partnerships focused on school safety: The Baltimore example. Washington, D.C.: The Journal of Negro Education, Vol. 65, No. 3. Educating Children in a Violent Society, Part I. pp. 369-374.

Sanders, M. (1998). The effects of school, family and community support on the academic achievement of african american adolescents. Urban Education, Volume 33, No. 3. p. 385-409. Corwin Press Inc.

Sanders, M. (2006). Building school-community partnerships: Collaboration for student success. Corwin Press. Thousand Oaks, CA: SAGE Publications.

Sanders, M. G., \& Simon, B.S. (2002). A comparison of program development at elementary, middle, and high schools in the National Network of Partnership Schools. Lincoln: IL: The School Community Journal, 12(1), 7-27.

Sanders, M. (2005). Building bridges toward excellence: community involvement in high schools. Johns Hopkins University. Karla C. Lewis SERVE Regional Education Laboratory. North Carolina: The University of North Carolina Press.

Senge, P., Kleiner, A., Robert, C., Ross, R, Smith, B. (2002). The fifth discipline fieldbook: Strategies and tools for building a learning organization. New York: Doubleday.

Sheldon, S. B. (2003). Linking school-family-community partnerships in urban elementary schools to student achievement on state tests. Springer, Netherlands: Urban Review, 35(2), 149-165.

Sheldon, S. B., \& Epstein, J. L. (2002). Improving student behavior and discipline with family and community involvement. Education in Urban Society, 35(1), 4-26. 
Sheldon (2010). Improving student attendance with school, family, community partnerships. The Journal of Educational Research, 100:5, 267-275,John Hopkins University.

Sheldon, S. B., \& Van Voorhis, F. L. (2003). Partnership programs in U.S. schools: Their development and relationship to family involvement outcomes. School Effectiveness and School Improvement, 15, 125-148. Taylor and Francis.

Sheldon, S. and Epstein, J. (2005) Involvement counts: Family and community partnerships and mathematics achievement. The Journal of Educational Research, Vol. 98, No. 4, pp. 196-206. Taylor \& Francis, Ltd.

Shein. E. (2010). Organizational culture and leadership. Jossey-Bass. San Francisco, CA.

Shor, I. (1992). Empowering education: Critical teaching for social change. Chicago: University of Chicago Press.

Sitton Hays, P. (2011). Narrowing the gap: Three key dimensions of site-based leadership: four Boston charter schools. Education and Public Society. SAGE

Stake, R. (2006). Multiple case study analysis. New York: Guilford Press.

Stelmcach, B. (2004). Unlocking the schoolhouse doors: Institutional constraints on parent and community involvement in a school improvement initiative. Canadian Journal of Educational Administration and Policy, Issue \#31. University of Alberta

Stelmach, B. (February 2007). A case study of three mothers' experiences in the Alberta initiative for school improvement: Having a voice versus getting a hearing. International Journal of Leadership in Education: Theory and Practice.

Tyack, D., \& Cuban, L. (1997). Tinkering toward utopia: A century of Public school reform. Cambridge, MA. Harvard University Press.

Wenger, E., McDermott, R., Snyder, W. (2002). Cultivating communities of practice. Cambridge, MA. Harvard Business School Press.

Westbury, (2008). Making curricula: Why do states make curricula and how? The SAGE Handbook of Curriculum and Instruction. New York: SAGE Publications.

United States Congress. (1965). Elementary and secondary education act. 1965

U.S. Department of Education. (2001). No child left behind act of 2001. Retrieved on May 9, 2008 at http://www2.ed.gov/policy/elsec/leg/esea02/beginning.html 
U.S. Department of Education. (2009). Race to the Top program: Executive Summary. Washington, D.C. Retrieved from on October 14, 2011 from http://www2.ed.gov/programs/racetothetop/executive-summary.pdf

U.S. Department of Education. (2014). Title I. Retrieved on May 13, 2014. http://www2.ed.gov/policy/elsec/leg/esea02/pg1.html

Wang, J.; et. al (2010). Bold ideas for improving teacher education: What we see, hear and think. Journal of Teacher Education, 61(1-2) 3-15. American Association of Colleges for Teacher Education. SAGE Publications.

Wenger, E. (1998). Communities of practice: Learning, meaning, and identity: learning in doing: social, cognitive and computational perspectives. New York: Cambridge University Press.

Wenger, E., McDermott, R. and Snyder, W. (2002) Cultivating communities of practice. Cambridge, MA: Harvard Business Press.

West Virginia Department of Education. (2013). School improvement technical assistance manual: A handbook for continuous improvement. Office of School Improvement.

Yin, R. (2009). Case study research: Design and methods. Applied Social Research Methods Series, Volume 5. California: Sage Publications. 